Louisiana State University

LSU Digital Commons

1991

\title{
An Analysis of Sequential Patterns of Instruction in Piano Lessons.
}

Donald Ray Speer

Louisiana State University and Agricultural \& Mechanical College

Follow this and additional works at: https://digitalcommons.Isu.edu/gradschool_disstheses

\section{Recommended Citation}

Speer, Donald Ray, "An Analysis of Sequential Patterns of Instruction in Piano Lessons." (1991). LSU Historical Dissertations and Theses. 5209.

https://digitalcommons.Isu.edu/gradschool_disstheses/5209

This Dissertation is brought to you for free and open access by the Graduate School at LSU Digital Commons. It has been accepted for inclusion in LSU Historical Dissertations and Theses by an authorized administrator of LSU Digital Commons. For more information, please contact gradetd@lsu.edu. 


\section{INFORMATION TO USERS}

This manuscript has been reproduced from the microfilm master. UMI films the text directly from the original or copy submitted. Thus, some thesis and dissertation copies are in typewriter face, while others may be from any type of computer printer.

The quality of this reproduction is dependent upon the quality of the copy submitted. Broken or indistinct print, colored or poor quality illustrations and photographs, print bleedthrough, substandard margins, and improper alignment can adversely affect reproduction.

In the unlikely event that the author did not send UMI a complete manuscript and there are missing pages, these will be noted. Also, if unauthorized copyright material had to be removed, a note will indicate the deletion.

Oversize materials (e.g., maps, drawings, charts) are reproduced by sectioning the original, beginning at the upper left-hand corner and continuing from left to right in equal sections with small overlaps. Each original is also photographed in one exposure and is included in reduced form at the back of the book.

Photographs included in the original manuscript have been reproduced xerographically in this copy. Higher quality 6" $\times$ 9" black and white photographic prints are available for any photographs or illustrations appearing in this copy for an additional charge. Contact UMI directly to order.

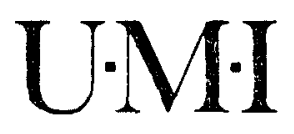

University Microfilms International

A Beil \& Howell Information Company

300 North Zeeb Road. Ann Arbor. MI 48106-1346 USA

$313 / 761-4700 \quad 800 / 521-0600$ 

Order Number 9207531

An analysis of sequential patterns of instruction in piano lessons

$$
\text { Speer, Donald Ray, Ph.D. }
$$

The Louisiana State University and Agricultural and Mechanical Col., 1991

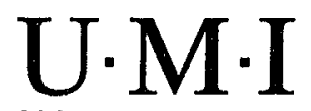

300 N. Zeeb Rd.

Ann Arbor, MI 48106 


\title{
AN ANALYSIS OF SEQUENTIAL PATTERNS OF INSTRUCTION IN PIANO LESSONS
}

\author{
A Dissertation \\ Submitted to the Graduate Faculty of the \\ Louisiana State University and \\ Agricultural and Mechanical College \\ in partial fulfillment of the \\ requirements for the degree of \\ Doctor of Philosophy \\ in \\ The School of Music
}

\author{
by \\ Donald Ray Speer \\ B. M., Louisiana College, 1983 \\ M. M., Southern Illinois Univerisity at Edwardsville, 1985 \\ August 1991
}




\section{DEDICATION}

This work is dedicated to my wife, Alesia, whose unwavering commitment to this project and unfalling support made it all possible; and to my children Colleen, Jordan, and David. 


\section{ACKNOWLEDGMENTS}

The author gratefully acknowledges Dr. Cornelia Yarbrough for her kindness and support in the guidance of every step of this project. With deepest thanks for opening my eyes to the world of research!

Thanks also to professors Jane Cassidy and James Byo for their expertise in teaching, and their commitment to make the issues in teaching and research more clearly understood.

Gratitude is also expressed to Dr. Jack Guerry for his patience and understanding, and for allowing me the freedom to follow my convictions.

The two other members of my final examination committee: Kathleen Rountree and Karen Hamblen, who were very helpful with their comments and suggestions.

The Baton Rouge Piano Teachers Association for their participation, support, and continued interest in progress for the field of piano teaching. 


\section{TABLE OF CONTENTS}

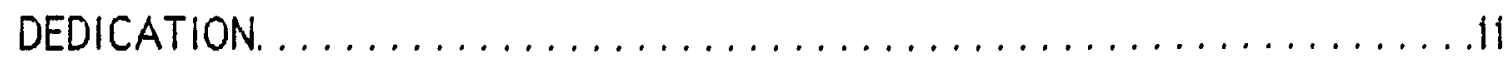

ACKNOWLEDGMENTS $\ldots \ldots \ldots \ldots \ldots \ldots \ldots \ldots \ldots \ldots \ldots \ldots \ldots$

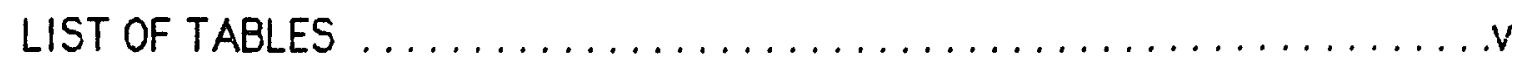

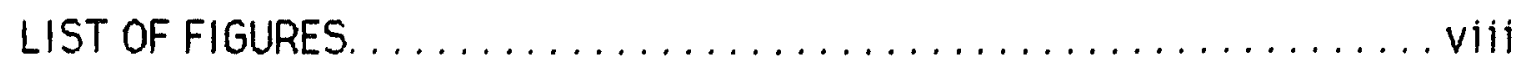

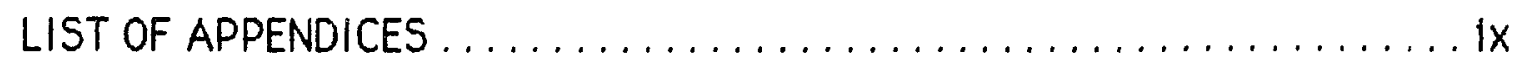

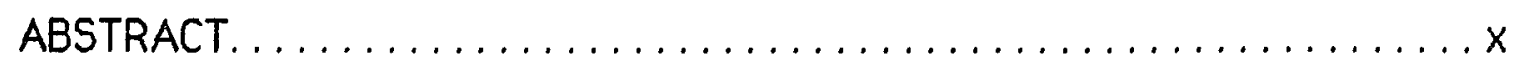

CHAPTER 1

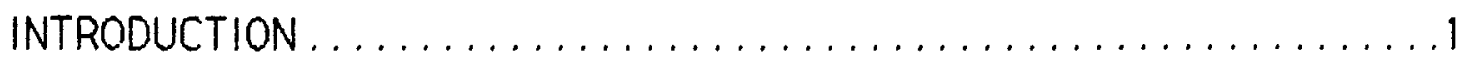

Statement of the Problem $\ldots \ldots \ldots \ldots \ldots \ldots \ldots \ldots \ldots \ldots$

Need for the Study. ........................... 6

Limitations............................... 8

Review of Literature $\ldots \ldots \ldots \ldots \ldots \ldots \ldots \ldots \ldots \ldots$

Summary .................................. 19

CHAPTER 2

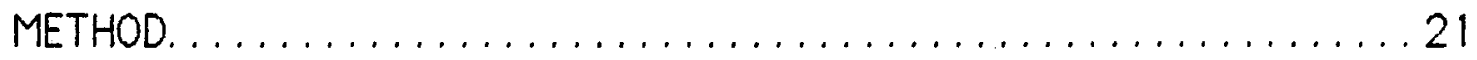

Subjects................................ 21

Procedure..................................21

Analysis of Lessons ..............................23

CHAPTER 3

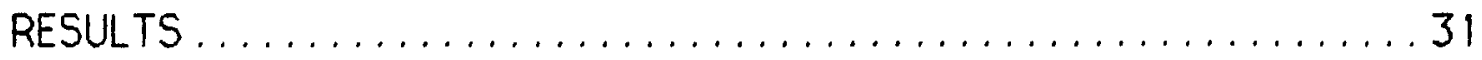

CHAPTER 4

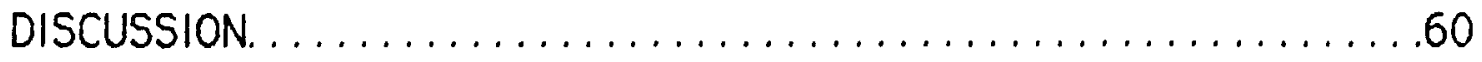

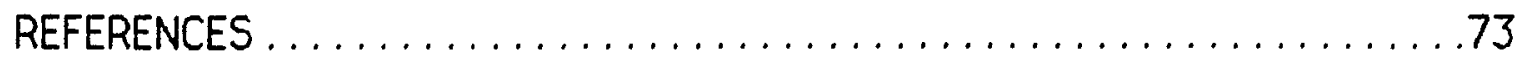

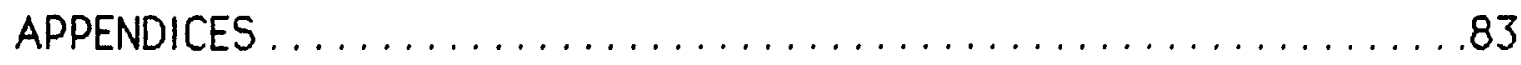

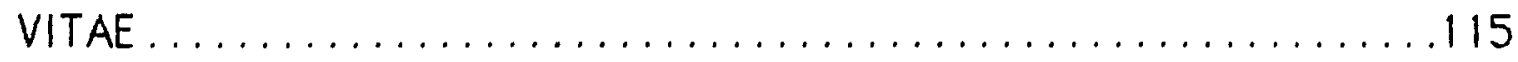

iv 


\section{LIST OF TABLES}

Table page

1. Mean Percentages of Time Spent in Teaching Pattern Components.

2. Mean Percentages of Time Spent in Teaching Pattern

Components by Siudent Age, Experience, and Perceived Ability.

3. Analysis of Variance for Teacher Presentation of Musical Information Comparing Younger and Older Students.

4. Analysis of Variance for Teacher coaching Comparing Younger and Older Students.

5. Analysis of Variance for Academic Teacher Talk Comparing Younger and Older Students.

6. Analysis of Variance for Teacher Direction Comparing Younger and Older Students.

7. Analysis of Variance for Teacher Direction Comparing "Average" and "Better" Students

8. Anaiysis of Variance for Total Teacher Talk Comparing Younger and Older Students.

9. Analysis of Variance for Total Student Participation Comparing Younger and Older Students.

10. Analysis of Variance for Student Performance Comparing Younger and older Students. 
11. Analysis of Variance for Total Student Participation Comparing Less-Experienced and More-Experienced Students.

12. Analysis of Variance for Student Performance Comparing Less-Experienced and More-Experienced Students.

13. Analysis of Variance for Overall Approvals Comparing Teacher Experience and Student Experience.... . 42

14. Analysis of Variance for Overall Disapprovals Comparing Teacher Experience and Student Experience. ... . 44

15. Analysis of Variance for Specific Verbal Approvals Comparing Teacher Experience and Student Experience.... . 45

16. Analysis of Variance for Non-Specific Verbal Approvals Comparing Teacher Experience and Student Experience. ... . 46

17. Analysis of Variance for Non-Specific Verbal Disapprovals Comparing Teacher Experience and Student Experience.... . 48

18. Analysis of Variance for Specific Verbal Disapprovals Comparing Teacher Experience and Student Experience.... . 50

19. Comparison of Overall Mean Percentages of Frequency and Time Spent in Verbal Reinforcement . ............. 52

20. Analysis of Variance for Student Verbalization Comparing Teacher Experience and Perceived Student Ability. 
21. Analysis of Variance for Student Performance Comparing Teacher Experience and Perceived Student Ability................................ 55

22. Analysis of Variance for Sequential Patterns Comparing Percentages of Complete/Correct, Complete/Incorrect, and Incomplete Patterns......... 57

23. Comparison of Means for Complete/Correct, Complete/Incorrect, and Incomplete Patterns. 57

24. Spearman Rank Correlation Coefficients Comparing Expressed Teacher Values to Observed Teacher Behaviors. 


\section{LIST OF FIGURES}

Figure

page

1. Operational Definitions of Sequential Patterns ........24

2. Eifect of Teacher Experience and Student Experience on Percentage of Overall Approvals ................43

3. Effect of Teacher Experience and Student Experience on Percentage of Overall Disapprovals

4. Effect of Teacher Experience and Student Experience on Percentage of Non-specific Verbal Approvals. . . . . . 44 47

5. Effect of Teacher Experience and Student Experience on Percentage of Non-specific Verbal Disapprovals ..... . .49

6. Effect of Teacher Experience and Student Experience on Percentage of Specific Verbal Disapprovals ........ 51

7. Effect of Teacher Experience and Perceived Student Ability on Student Verbal Behavior When Compared to Totai Student Participation

8 Effect of Teacher Experience and Percelved Student Ability on Student Performance when Compared to Total Student Participation. . 


\section{LIST OF APPENDICES}

Appendix

page

A. Teacher/Student Information Sheet. ...............83

B. Teacher Questionnaire ....................... 85

C. Transcript of Sample Lesson:

Younger Student; Less-Experienced Teacher . . . . . . . . . . .87

D. Transcript of Sample Lesson:

Older Student; More-Experienced Teacher............. 104 


\section{ABSTRACT}

The purpose of this study was to investigate verbal behaviors of independent piano teachers in the setting of the private piano lesson. Twenty-five piano teachers from southeast Louisiana participated in the study. Teachers recorded the individual lessons of two students on audiotape. Verbatim transcripts were developed from a total of 47 recorded lessons. Transcripts were coded, identifying verbal behaviors with regard to components of sequential patterns established by Yarbrough: and Price $(1981,1989)$. Verbal behaviors were analyzed for time spent in the categories of teacher presentation, student participation, and teacher reinf orcement. Frequencies were obtained for the number of complete/correct, complete/incorrect, and incomplete teaching patterns observed

Results demonstrated significant differences due to student age in the areas of overall presentation of musical information, teacher talk, and coaching by the teacher, as well as student participation. Results also indicated that students perceived as "average" by their teachers received significantly more directive comments than students perceived as "better."

Significant interactions were observed in the area of verbal teacher reinforcement between the variables of student experience and teacher experlence. Results showed that teachers with more than 18.5 years of experience were more disapproving to students with more than 3.5 years of playing experience. Less-experienced teachers not only exhibited more approvals to more-experienced students, but were more specific with approvals overall than their more-experienced colleagues. 
Observation of frequencies of occurrence of teaching patterns revealed relatively low frequencies of complete/correct patterns of teaching when compared to complete/incorrect and incomplete patterns observed.

A post-hoc questionnaire dealing with various components of teaching patterns was completed by 21 of the 25 teachers. Spearman Rank correlation comparing teacher opinions to teacher behaviors revealed little, if any correlation between the expressed opinions and observed behaviors of the teachers. 


\section{CHAPTER 1}

Effective teaching which results in positive, permanent changes in students has long been a primary concern of educators in all fields Widespread attention has been focused on the teaching field by members of society in general, as they have come to the realization that effective instruction is fundamental to the overall well-being of society as a whole. As a result of this continued interest in a better educational system, teachers have been under increasing demands to prepare more thoroughily, establish and achieve higher goals, and produce better students.

One outgrowth of this demand for improved education has been the development of "models" of teaching, as identified by Joyce and Weil (1986). Four primary "families" of teaching models were identified through the work of these scholars. The "Information-Frocessing" family was identified as a category consisting of those models of teaching which were concerned primarily with how students processed iniormation from their environment. This group of models included the learring theories of Bruner, Goodnow, and Austin (1967) and Ausubel (1963), which were designed to help students acquire concepts considered necessary for the organization of information. Studies by Piaget (1952), Sigel (1969), and Kohiberg (1976) which centered upon student intellectual development, were also included in this "family" of teaching models.

The "Personal" and "Social" families of teaching models were identified by Joyce and weil as those consisting of structures which emphasized the needs of the individual or group, allowing it essentially to develop on its own terms. The ideas of Rogers (1979), Gordon (1961), and 
Glasser (1965) are examples of "Personal" ieaching models derived from goals of creativity and personal development. The theories of Dewey (1916) formed the basis of the "Social" family, consisting of a wide range of teaching models based on concepts of society and interpersonal relationships. The role of the teacher in both "Personal" and "Social" categories of teaching models was identified primarily as one of being a "facilitator," rather than a "director" in the learning process.

Finally, the "Behavioral Systems" family identified by Joyce and Weil consisted of those models of teaching based on a stimulus-responsereinforcement theory of learning. One such teaching model, labeled "Cybernetics" or the "Training Model," placed an emphasis on mastering a skill through information, demonstration, practice, feedback, and coaching in order to attain a goal of moving from theory to practice in a specific area of learning.

Central to the "Behavioral Systems" group of teaching models was the development of a model identified by Rosenshine (1976) and Carnine (1979) as "Direct Instruction." Benjamin (1981) identifies the components of the Direct-Instruction model as:

1) clear cues as to what is to be learned,

2) intensive student participation,

3) positive reinforcement of the lessons, and

4) immediate feedback from the teacher (Benjamin, p. 71).

Becker (1986) added, "Procedures [for direct-instruction] are favored that reduce wasted time and rasten the teaching of given objectives" (Becker, p. 166). The direct-instruction model of teaching has been investigated extensively and applied to music through the work of Yarbrough and Price (1981, 1989), where the model has become known as "Sequentlal Patterns" of instruction. 
Much of the research centering upon the issue of teacher effectiveness has been conducted with reference to the development of and experimentation with these established models of teaching (Jovce, Brown, \& Peck, 1981). An integral part of this research has been the necessary focus on the specific role of the teacher. Lancaster (1974) has listed several reasons why teachers should be evaluated, two of which are 1) to help improve teaching, and 2) to develop some standards of acceptable performance. In addition, Medley (1979) has presented the viewpoint that there are two important ways to improve the effectiveness of teachers: 1) improving the way in which teachers are evaluated, and 2) changing the way teachers are educated. He continued by stating that either of these two can only be achieved when based on accurate information, i.e., information based on research.

With this rationale, the subject of teacher effectiveness has been the focus of a relatively large body of recent research. Early research in this area tended to rely upon descriptions and rating scales which listed characteristics possessed by those perceived to be effective teachers. A limitation of this type of investigation stemmed from the fact that it was based primarily on perceptions, therefore utilizing a dependent measure which could not be considered reliable. Researchers then began to direct attention tơ the mianner in which subject matter was being taught, exploring various methodologies and their relative ef fectiveness to each other. A drawback to this type of research also became evident, since results were derived largely from pupil achievement, rather than teacher performance.

The observation of teacher behavior along with student achievement became the regular focus of researchers in the 1960's. Known as "process-product" research, this mode of investigation was centered 
around the observation of stable teaching behaviors which occurred over time. Grant and Drafall (1991) state,

Process-product research has demonstrated clearly that teachers make a difference in the learning levels of their students, and that certain observable teaching behaviors affect student achievement positively. (p. 32).

Furthermore, Brophy and Good (1986) identified two results which recur throughout studies in teacher effectiveness. They are:

1) academic learning is influenced by amount of the time that students spend engaged in appropriate academic tasks, and 2) students learn more efficiently when their teachers first structure new information for them and help them relate it to what they already know, and then monitor their performance and provide corrective feedback during recitation, drill, practice, or application activities (p. 366).

Flanders (1969) has been credited with a significant contribution in the area of process-product research through the development and application of "Interaction Analysis," a method of observing, codifying, and categorizing teacher behaviors exhibited in a classroom environment. The advantage of Interaction Analysis was its provision for quantifying verbal communication observed in the learning environment. Verbal behaviors were more specifically identified in the categories of teacher talk, student talk, and silence or confusion.

Haigh and Katterns (1984) have stated, "Effective teachers ... recognize that their teaching effectiveness will depend on a preparedness to experiment with, analyze, and evaluate their own patterns of thought and action" (p. 24). Brophy (1979) has expressed the need for continuing to establish and expand the empirical base of reliable information regarding 
teacher effectiveness. Furthermore, Rosenshine and Furst (1973) have suggested that educational researchers follow an approach to inquiry beginning with descriptive studies of an event, followed by preliminary testing using correlation techniques, eventually resulting in the employment of experimental methods in a given environment.

\section{Statement of the Problem}

The role of the independent piano teacher is unique within the realm of music education. Traditional practice has long promoted the advantage of individual instruction. Because of the individualized nature of study, the personal behaviors of teacher and student play a substantial role in the learning environment.

In spite of the fact that keyboard instruction as a profession has been present for centuries, the training of piano instructors with respect to teaching behaviors is relatively new. Teachers exhibit a wide variety of backgrounds and levels of education and training.

Very little empirical investigation has been conducted in the area of piano instruction, resulting in a lack of research-based information from which conclusions can be drawn and direction can be estabiished. It has been necessary to transfer from other areas of education the information gained through research concerning teacher activity and teacher effectiveness.

The purpose of the current study was to investigate teacher effectiveness in the setting of the private piano lesson through the application of research techniques used in general education and music education. Specifically, components of sequential patterns of teaching were studied, including an investigation into the time spent in specified 
categories of teacher presentation, student participation, and teacher reinforcement. The following questions were addressed:

1. How do observed events in the private piano lesson relate to the direct-instruction model and sequential patterns of teaching? What percentage of the private piano lesson is structured in complete teaching patterns (task presentation, student response, teacher feedback)?

2. What percentage of the private piano lesson is spent in task presentation? What is the content of those task presentations?

3. What percentage of the private piano lesson is spent in student performance and verbalization?

4. What percentage of the private plano lesson includes teacher feedback in the form of approvals and disapprovals?

5. What percentage of the private piano lesson includes specific and non-specific feedback?

6. Is there a difference in the observed occurrence of components of the teaching pattern related to the variables of student age, student experience, perceived ability of the student, and/or teacher experience?

\section{Need for the Study}

While researchers in the field of education have made great strides in the area of teacher effectiveness, those in the area of piano instruction seem to have focused attention primarily on teaching materials and cognitive aspects of teacher behavior. Chronister (1977) stated,

There can be no doubt that the great amount of fascinating teaching material that has been developed in the past fifty years helps us to be better teachers. If piano teaching fails, we can hardly blame the material, whatever the approach. All these 
materials are called methods, but they are not methods. They are only the books teachers use - the way they are taught is the method. Unfortunately, there has been more progress in teaching materials than in teaching methods during the past fifty years (p. 3).

In addition to the fact that piano instructors appear historically to have emphasized the importance of teaching materials, a brief survey of ideas centered upon teacher effectiveness revealed an emphasis on the cognitive, rather than behavioral aspects of piano teaching. For example, Camp (1981) investigated the learning theories of Mursell, Piaget, and Bruner, in addition to ideas presented in gestalt psychology to formulate his own approach to piano teaching. Penick (1988) promoted three areas of "awareness" which should be developed in students by teachers at the piano lesson, consisting of visual, physical, and aural aspects of experience. Robert (1981) suggested criticism, demonstration, analysis, and inspiration as important approaches to successful teaching.

Even those approaches to piano teaching which have of fered any behavioral techniques whatsoever to the piano teacher appeared to do so in general terms, rather than through specific techniques. For example, Bastien (1977) suggested five "personality needs" for the prospective piano teacher, consisting of self-confidence, a pleasant attitude, enthusiasm, encouragement, and patience. Robinson and Jarvis (1967) listed twenty-one "Principles of Good Teaching," including two general references concerning reinforcement which stated:

1) Employ motivation (hope of reward) to strengthen or "reinforce" learning, and

2) Make corrections diplomatically and in a manner that will not cause the pupil to be embarrassed or resentful (p. 32). 
Skaggs (1981) made similar recommendations, including:

1) Show your students that you care about them,

2) Reinforce good behavior, and

3) Encourage students; don't be negative (p.631).

Countless techniques designed to achieve effective teaching in the field of piano instruction have been suggested; yet most of the information disseminated has been based on personal experience and "common sense." very little information has been derived from research-based investigation of the subject. Most empirically-based investigations in the field of private piano instruction have been limited to historical surveys and surveys of factors dealing with pedagogy instructors (Kowalchyk, 1989), parental attitudes (Power, 1990), attitudes surrounding the availability and use of technology in the piano studio (Young, 1990), and quantity of teacher training (Lorince, 1990).

To date, no study has addressed the issue of teacher behavior within the private piano lesson and its relationship to established models of teaching. Therefore, it was the purpose of the present study to investigate the verbal behavior of independent piano teachers within the context of specific components of sequential patterns of teaching.

\section{Limitations}

Certain limitations were applicable to this study on teacher behavior. First, the focus of the observations was centered upon verbal behaviors only, with very little consideration made toward non-verbal behaviors present within the private piano lesson.

Second, the current study was focused upon the verbal behaviors of only the teacher, with no emphasis or consideration made toward the 
quality of student participation or student achievement. The only factor of student participation observed in this study was a measure of the quantity of time spent in performance and verbalization.

Third, all students participating in this study were between the ages of 7 and 17, and were observed within the environment of the individual lesson-setting. Therefore, results may not be applicable in situations with pre-school and adult students, or within the context of group teaching.

Finally, it was not the intent of this study to define and/or identify effective and ineffective teachers on a general basis. It was the intent of this study to describe one aspect of teacher effectiveness as it was observed within a specific teaching environment. Therefore, results should not be generalized to label those teachers who participated in this study as effective or ineffective in an overall context.

\section{Review of Literature}

Many variables in the area of teacher effectiveness have been the subject of recent research. Borich (1986) identified and discussed six models for classroom research, including the logic behind the processproduct model. Brophy (1979), Brophy and Good (1986), and Rosenshine (1976) have presented summaries of process-product research, including discussions concerning the direct-instruction model of teaching. Single (1990) organized an overview of research-based information around the three components of teaching patterns (i.e., teacher presentation, student response, and teacher feedback). Grant and Drafall (1991) reported on recent teacher effectiveness research as it related specifically to the area of music education. Difficulties associated with research in teacher 
effectiveness have been presented as well (Berliner, 1976; Good, 1979).

The ability to change teacher behavior was investigated in a study by Good and Brophy (1974), in which a method of presenting teachers with feedback in a non-threatening environment was implemented. Results from this study showed an increase in both quantity and quality of targeted teacher behaviors. In a similar study, Sparks (1988) explored the relationship between teacher attitudes and subsequent changes made in classroom teaching. She found that a measure of the philosophical acceptance of new behaviors by teachers functioned as an important predictor of whether or not changes in behavior would occur. Mitchell (1990) observed the lessons of four reading teachers over a period of ten sessions and conciuded that, although teachers in the study shared similar beliefs about reading, they varied widely in the application of those beliefs. A study by Yarbrough, Price, and Bowers (1990) investigated the values held by tweive experienced music teachers concerning researchbased rehearsal skills. Results revealed not only an increase in researchbased rehearsal skills following the dissemination of results of research in that area, but also a high, positive, and significant correlation between teacher values and teacher behaviors.

Research has shown that many teacher attitudes are expressed, either intentionally or unintentionally, through subsequent teacher behavior. Silberman (1969) interviewed ten third-grade teachers, acquiring information regarding feelings of "attachment", "concern", "indifference", and "rejection" toward specific students in their classes. The researcher then observed the teachers in classroom situations and concluded that the attitudes of "concern" and "indifference" appeared to have clearer expression through teacher behavior than attitudes of "attachment" and "rejection" toward students. In a subsequent study of nine first-grade 
teachers, Good and Brophy (1972) discovered that students with whom teachers felt "attached" were primarily high-achievers. Students in this group also received extra support from the teacher in subtie ways. In addition to this finding, the researchers reported that teachers in this study most of ten felt "concern" toward female low-achievers, and "rejection" toward male low-achievers.

The observation of additional inconsistencies in teacher behavior toward students in a variety of conditions has been widely reported. In a three-year longitudinal study, Rist (1970) discovered that teacher attitudes influenced student seating arrangements in a school with lowerclass students. In an investigation of 24 first-and third-grade classes, Friedman (1976) reported that middle-class students received significantly more non-verbal reinforcements than lower-class students. However, there was no difference in the frequency of verbal reinforcements observed.

Research showing a relationship between teacher behavior and gender of the student is well-established. Earlier studies using student opinions indicated that boys were perceived by their classmates to be the recipients of more negative comments by the teacher (Jackson \& Lahaderne, 1967) and recognized themselves that they were more of ten the recipients of disapproving comments by the teacher (Meyer \& Thompson, 1956). Contrary to these findings, Davis and Slobodian (1967) reported no significant differences between the treatment of boys and girls during direct observation of classes. A more recent observation of 100 classes by Sadker and Sadker (1985) indicated that boys were likely to receive more praise, attention, and academic help than girls in a classroom setting. The researchers also reported that in a second phase of the same study, 60 teachers were able to eliminate biases based on gender af ter 
only four days of training.

Differences in teacher behavior toward students of differing abilities have been observed as well (DeGroat \& Thompson, 1949). Heller and White (1975) concluded after 30 hours of observations with ten teachers that teachers were more disapproving with low-ability classes. The higher frequencies of disapproving comments were most of ten attributed to the area of social behavior in the low-ability classes. Brophy and Good (1970) discovered that teachers demanded more performance and were more likely to praise those students in whom they placed high expectations. Students receiving low expectations from the teachers were less likely to receive praise, even when they performed appropriately.

Studies investigating the differences between experienced and inexperienced teachers have been numerous (Berliner, 1986). Housner and Griffey (1985) reported that experienced and inexperienced teachers appeared to vary widely in the decision-making strategies employed in planning for and teaching physical education activities. Experienced teachers appeared to make more planning decisions concerning assessment, observing student performance, providing feedback to students, managing student behavior, focusing student attention and demonstrating motor skills. Experienced teachers also anticipated situations better, and demonstrated a larger number of contingencies to deal with specific situations.

In a study involving 20 music teachers, Moore (1976) compared the use of teaching time between beginning and experienced teachers. He found that beginning teachers spent more time preparing during class time than did experienced teachers, while experienced teachers allowed more time for discussion with children. Experienced teachers also spent more time giving instructions and were generally more positive in the type of 
feedback employed. Both beginning and experienced teachers expressed more disapprovals for social behavior and more approvals for academic behavior. The researcher discovered that both beginning and experienced instructors spent approximately one-half of the class time in musical performance. However, in a related study by Wagner and Strul (1979), significant differences in the use of teaching time between experienced teachers, teaching interns, and undergraduate students were found in only one area. The investigators reported that experienced teachers spent less time giving directions than inexperienced teachers.

In a study comparirig the use of time by experienced elementary music teachers in the United States and Britain, Moore (1981) discovered no significant differences between the groups in 17 out of 22 comparisons. The comparisons primarily examined the content and organization of music lessons, but included an observation of time spent in teacher talk as well as a measure of frequencies of approvals and disapprovals. Results indicated that both American and British music specialists gave significantly more approvals than disapprovals, more academic than social feedback, and more social than academic disapproval.

Teacher effectiveness in the field of music has been investigated primarily through the observation of verbal and non-verbal teacher behaviors. In the realm of non-verbal behaviors, researchers have most recently focused on what has been labeled teacher "magnitude," "intensity," or the "style" of delivery as a factor in teacher effectiveness. Yarbrough (1975) operationally defined and explored teacher "magnitude" through the observance of high and low levels of specific conductor behaviors in a choral rehearsal setting. In studies of teacher intensity, researchers concluded that the concept of teacher intensity can be defined, and can also be recognized, demonstrated, and easily taught with 
a high degree of accuracy (Byo, 1990; Madsen, Standley, \& Cassidy, 1989). In a study examining student attentiveness in high school ensemble rehearsals, Yarbrough and Price (1981) reported a strong relationship between a lack of eye contact by the teacher and off-task behavior by students. In addition to results obtained, the researchers recommended further analysis of teacher behavior and student response in relation to other variables such as age and ability.

A relatively large portion of research dealing with the effectiveness of music teachers has centered upon the observation of verbal content within the lesson setting. Verbal behavior by conductors and subsequent effects on student attitudes has been studied by Murray (1975), Price (1983), and Carpenter (1988). All three studies concluded that student attitude was more positive with more approving conductors.

Other studies have looked specifically at verbal reinforcement as a variable of teacher effectiveness in music settings. In a study comparing three different teaching styles, 188 elementary education majors and 99 music education majors evaluated transcripts developed from videotaped teaching segments and indicated a preference for teaching which included positive feedback as an element (Wolfe \& Jellison, 1990). Price (1989a) reported that approving reinforcements were rated as components of better teaching by both graduate students and experienced music teachers. In spite of these findings, observations of actual rehearsal situations have revealed that reinforcement is generally more disapproving than approving, with a higher ratio of specific comments occurring in conjunction with disapprovals rather than approvals (Carpenter, 1988; Yarbrough \& Price, 1989).

In a comparison of elementary music classes and regular elementary classes, Forsythe (1975) found that approval ratios above $75 \%$ produced 
more on-task behavior than $75 \%$ disapproval ratios in both settings. Along the same lines, Madsen and Alley (1979) discovered that music educators and therapists trained in behavioral techniques made use of higher ratios of approval, and consequently achieved more student on-task behavior than untrained teachers and therapists.

A similar study compared the perceptions of students trained in behavioral techniques to the perceptions of untrained students (Madsen \& Duke, 1985a). The researchers found that trained sub jects viewed teacher approval as being effective and beneficial, while untrained observers more of ten perceived approvals as being insincere, ineffective, or unnecessary. Duke (1986) investigated the reactions of 53 education majors as they responded to videotaped examples of appropriate and inappropriate student behavior. He found that subjects recommended negative teacher feedback following inappropriate student behavior (27\%) significantly more than positive teacher feedback following appropriate student behavior (5\%), and subjects suggested verbal feedback much more of ten than non-verbal feedback as an appropriate response to all student activity. In addition to these findings, Duke reported that subjects recommended positive feedback more frequently to younger students than they did to older students. Subjects also had difficulty clearly specifying observable behavior.

Researchers have also explored the structure and organization of verbal components of music instruction in several contexts. The establishment of "sequential task hierarchies" or "proactive" teaching sequences has been investigated by Duke and Blackman (1989, March). The emphasis in this line of research encouraged the teacher to structure events with a high probability of student success, therefore establishing an environment conducive to the use of high rates of approval. Duke and 
Madsen (1991) evaluated the audiotapes of lessons taught by 81 novice "teachers" (nonmusic majors enrolled in a guitar course). In this study, 40 of the 81 "teachers" were provided a detalled 12-step task hierarchy to be used in teaching the lesson. Results indicated that students whose teachers followed the task hierarchy performed more accurately (87\%) than those students whose teachers were not given a task hierarchy to follow (76\%). In addition to these findings, the researchers reported that $64 \%$ of the total teacher feedback was non-specific, while $21 \%$ was specific in nature. Furthermore, most of the time spent in verbal teacher reinforcement was observed in the area of non-specific approvals (60\%), followed by speciric disapprovals (14\%).

Jellison and Wolfe (1987), and Wolfe (1989, March) examined verbal and visual training to increase the use of "antecedents" (teacher presentations), "consequents" (teacher responses) and complete teaching units among music and elementary education majors. The researchers found that verbal training and visual prompts were effective in increasing the use of antecedents and consequents by subjects.

The structure and organization of verbal behavior in the music setting has been influenced greatly by the observation, identification, development, and implementation of "sequential patterns" of instruction. Like the "direct instruction" model on which it has been based (Carnine, 1979; Peterson, 1979; Rosenshine, 1979), sequential patterns make use of an academically-focused, teacher-directed environment in which instructors provide feedback to student activity (Price, 1985; Yarbrough \& Price, 1981, 1989).

Price (1983) concluded that complete patterns of teaching were effective in enhancing student performance and student attentiveness. In an analysis of verbatim transcripts developed from 79 choral and band 
rehearsal settings, Yarbrough \& Price (1989) discovered that most teachers spent more time using incomplete rather than complete (presentation, response, feedback) teaching patterns. Choral conductors reportedly spent $34 \%$ of the total rehearsal time employing correct teaching patterns, while only $18 \%$ of band directors were observed to do the same. Only one-fourth of rehearsal time incorporated the presentation of musical information and appropriate verbal reinforcement. Another finding of this study indicated that experienced teachers were highly disapproving, while preparatory teachers were highly approving.

Research has indicated that students prefer a teaching style which incorporates a complete "pattern," consisting of task presentation, student response, and teacher feedback (Jellison \& Wolfe, 1987). In a related study by Price and=/ Yarbrough (1990), 48 transcripts of excerpts from choral and instrumental rehearsals were evaluated by graduate music majors, experienced music teachers, and undergraduates who had completed some music teacher training. Results indicated an overall preference for teaching patterns which were initiated with academic information and completed with an approving reinforcement. Academic musical presentation was preferred over teacher direction, and patterns containing approvals were preferred significantly more than patterns which contained disapprovals or no feedback. Results of this study supported those reported by Price (1989a) in an earlier study. He also found that correct feedback was rated more highly than incorrect feedback.

In contrast to the numerous studies conducted in general music and large ensemble settings, few studies have focused on teacher behavior in the applied music environment. Duke (1987) investigated the effect of observation training on the perceptions of the effectiveness of applied 
music instructors. In this study, the observations of 50 trained music education and music therapy majors were compared to 50 untrained education majors with respect to their perceptions of time spent in an applied music lesson. Estimates of time were made in the areas of student talk, teacher talk, student performance, and teacher performance, as well as teacher approval, teacher disapproval, teacher instructions/explanations, and teacher performance/demonstration. Results indicated that observers varied widely in their perception of events, even with specific categories of observation. Furthermore, statements by subjects concerning disapprovals by the teacher outrumbered statements concerning approvals, although the applied instructor actually made more approval responses during the lesson.

Also in the area of applied music instruction, Schmidt (1989) explored the relationship of personality variables (as measured by the Myers-Briggs Type Indicator) to specific teacher behaviors in collegelevel applied music instructors. His investigation included a measure of approvals, disapprovals, reinforcement rates, teacher talk, teacher modeling, teacher questions, and pace. Results suggested that personality variables of the applied music teacher were significantly related to approvals, reinforcement rate, teacher modeling, and pace. Personality variables were not significantly related to the behaviors of disapproval, talk, or questioning

Arrau (1990) recently investigated the verbal behavior of six group piano teachers identified as "exemplary" by colleagues through a written survey. College and university teachers were observed instructing ten consecutive lessons to a first-semester group piano class for non-music majors. Results indicated that $79 \%$ of the total lesson time was spent in teacher activity. Teachers spent significantly more time giving directions 
(25\%) than any other behavior. Teachers were also found to be significantly more postive than negative in their use of reinforcement.

With respect to the private-lesson setting, Kostka (1984) observed 48 piano teachers in 96 private lessons, using an intervallic observation method devised for the study. Analysis of the lesson time indicated that most of the lesson was spent in student performance (56\%) and teacher talk (42\%). Reinforcement was given frequently, and most reinforcement was academic (92.1\%) rather than social (7.9\%). Results also revealed student age as a significant factor in observed differences among the twelve variables measured in this study. Younger students (through grade six) received the highest ratios and rates of approvals (54\% approval, every 33.4 seconds). Older students (grades seven through twelve) spent more time in student performance. Kostka also reported that interruptions of student performance were most of ten followed by teacher disapprova! of academic performance (83.1\% - younger students; $67.3 \%$-oider students). Teachers also interrupted for instruction ( $12 \%$ - younger; $22.4 \%$ - older), and least of ten to give approval (3.6\% - younger; $7.3 \%$ older). Effects of teacher interruptions on student attentiveness were not significant.

\section{Summary}

Empirical investigation of the verbal behavior of teachers in relationship to teacher effectiveness has been well-established. Extensive, systematic exploration of the direct-instruction model and sequential patterns of teaching has been conducted. Results of past research have indicated that sequentlal patterns of instruction have not only enhanced student performance and attentiveness, but have been 
preferred by students and teachers as well.

Researchers have also reported on the differential treatment of students by the teacher in the classroom setting. Differences in teacher behavior have been observed between students of different ages and abilities. Differences in teacher behavior based on teacher experience have also been discovered.

Relatively little research has been conducted in the area of teacher behaviors exhibited by the independent piano teacher. Most studies in teacher effectiveness have dealt with the observation and experimentation of factors outside the setting of the private piano lesson. To date, no study ias investigated behaviors of the independent piano teacher in relationship to components of sequential patterns of teaching. Therefore, the purpose of this study was to extend the work of Kostka and others by exploring more thoroughly the use of sequential patterns of instruction by teachers in the setting of the private piano lesson. 


\title{
CHAPTER 2
}

\author{
Method
}

\section{$\underline{\text { Subjects }}$}

Subjects for the current study were 25 independent piano teachers from the southeast Louisiana region. Average age of the subjects was 433 years, and teaching experience ranged from 5 to 40 years, with a mean of 18.5 years of experience in teaching. All subjects except two had completed music study in an undergraduate degree program, with twelve of the twenty-five subjects holding a graduate degree in the field of music. Sixteen of the twenty-five subjects held certification through the Music Teachers National Association. All subjects maintained active studios at the time of the study, with 19 of the 25 subjects teaching a total of 15 or more students each. Participation in the study was on a volunteer basis

\section{Procedure}

Subjects were asked to select two piano lessons to record on audiotape. The lessons were to be of two different students in individual lesson settings. One of the two students was to be younger than 11 years old, while the other was to be 11 years old or older. Subjects were also told to select one of the two students from what they considered to be the "better" students in their own studio, while the other was to be an "average" student. Because the teacher's perception of the student's 
ability rather than the actual ability was being considered, no criteria were given to the subjects concerning definitions for "better" and "average" students. However, teachers were encouraged to determine student status based on the students found within the teacher's own studio, without making comparisons to the studios of other teachers.

Subjects were provided 90-minute audiotapes (45-minutes per side), and were instructed to record the entire piano lesson, from the first interaction with the student to the last. Subjects were informed that the study involved an investigation of the "typical" piano lesson and, therefore, were encouraged to allow the lesson to proceed as normally as possible, including any and all interruptions that may have occurred. Subjects were asked not to make any changes in the regular lesson format, such as the inclusion of any more or less conversation, any more or less musical content, etc. At the completion of the task, subjects were asked to complete a survey requesting demographic information about themselves and each of the two students who were chosen to participate in the study (see Appendix A).

Audiotapes consisting of a total of 47 private piano lessons were returned for anialysis. Students included in the study ranged in age from 7 to 17 years, with a mean age of 10.9 years. Experience in piano lessons ranged from 6 months to 10 years, with an average experience of 3.6 years.

Af ter subjects returned the completed audiotapes and surveys, they were asked to complete a brief questionnaire eliciting their opinions about certain aspects of teacher and student behavior in the piano lesson. Content of the questionnaire specifically addressed teacher's opinions in relation to time spent in teacher presentation, student response, and teacher reinforcement (see Appendix B).

Verbatim transcripts were developed from each of the 47 individual 
lessons, consisting of a total time of 1663 minutes for all lessons. Transcripts were used to analyze, time, and count various aspects of the private piano lesson (see Appendices $C$ and $D$ ).

\section{Analysis of Lessons}

Complete transcripts of all lessons were developed and coded for components of sequential patterns. All teacher statements and student responses were coded according to criteria established in the Operational Definitions of Sequential Patterns (see Figure 1). Individual teacher statements were first classified as either 1 (teacher presentation) or 3 (teacher reinforcement), depending on whether they were understood to be either teacher-initiated comments or reactions to student activity. Teacher presentations (1) were then further classified as either presentations of academic musical information (1a), directions (1d), social task presentations (1s), or off-task statements (10). Teacher reinforcements (3) were classified as either approving ( $3 a$ ) or disapproving ( 3 d) statements. Approvals and disapprovals were further identified as being either specific (s) or non-specific ( $n$ ). Student activity (2) was categorized into performance $(2 p)$ and verbal $(2 v)$ responses. Verbal responses by students were not analyzed for specific content. 
Figure 1.

OPERATIONAL DEFINITIONS OF SEQUENTIAL PATTERNS

\section{Components of Sequential Patterns}

(1) Teacher Presentations - presentation of information by the teacher through statements, comments, and/or questions in the following categories:

la - academic musical task presentation

* comments which ask or tell the student to think about, listen to, or talk about musical, techrical, and/or performance aspects;

*teacher modeling (playing, singing, tapping, etc.);

*information regarding assignments, practice habits, etc.;

* counting beats during student performance;

*procedural aspects of the lesson; and

*recitals, concerts, and other activities both in and out of the studio which are musical in nature.

$1 d$ - direction

*telling or asking the student to play, including where to begin and who will play;

*counting beats prior to student performance to establish a beat, may end in "ready, go"

is - social task presentation

* comments or questions regarding general rules of behavior, not related to performance etiquette, etc. 
Figure I (cont'd.).

10- off task

* statements, comments, or questions which do not provide the student any information related to the previous categories.

*Includes social conversation, verbal mannerisms, and/or talking to oneself.

(2) Student Response

$2 p$ - performance (playing, singing, tapping, etc.)

$2 v$ - verbal ( student asking or answering a question, or making a statement)

(3) Teacher Reinforcements - Feedback given in response to student activity

3a-verbal approval (positive statement about student performance, student verbal response, or student social behavior; includes any positive response to student in any conversation)

$3 d$ - verbal disapproval (negative statement about student performance, student verbal response, or student social behavior; includes any negative response to student in any conversation)

(s) - Specific, exact feedback containing musical information

(n) - Non-specific, vague feedback containing no musical information 
Figure 1 (cont'd.).

Sequential Patterns

Complete - Teacher presentation of task (1a or 1d)

Student response (2)

Teacher reinforcement (3)

Correct: $1 a-2-3 a(s)$

or

$1 a-2-3 d(5)$

Incorrect: Any complete pattern which begins with a non-specific teacher direction (1d) or ends with a non-specific reinforcement ( $3 a n$ or $3 \mathrm{dn}$ ) is considered incorrect.

Incomplete - Any teacher-initiated sequence (beginning with an academic musical presentation or direction) which does not conclude with a teacher reinforcement for student response is considered incomplete.

Additional Definitions

Modeling - any occurrence of playing or singing by the teacher coaching - any teacher presentation or teacher reinforcement occurring simultaneously with student performance. 
In the analysis of verbal behavior, certain statements such as "OK," and "All right" appeared to serve several functions, depending on the context of the events in the lesson. These comments were considered to be non-specific teacher approvals ( $3 a n$ ) when they immediately followed a student response. The same statements were labeled as teacher direction (1d) when they followed a teacher task presentation ( 1 a) and immediately preceded a student response. At times, the comments appeared to function as verbal mannerisms, and were then categorized as off-task statements (10) when they occurred at times other than those specified above.

Reliability of the dependent measure was conducted by three independent observers on $25 \%$ of total lessons. Reliability coefficients were obtained by calculating agreements divided by agreements plus disagreements. Average reliability was 90 , with reliability over individual lessons ranging from .83 to .94

Total time in seconds was obtained for each of the 47 lessons in the study. Time analysis to the nearest $1 / 100$ th of a second was then conducted and recorded for each separate component of teacher verbal behavior and student activity observed within the lesson. Total times were computed for each of the following categories: teacher presentations of academic musical information (1a), direction (1d), social information (1s), of f-task comments (10); teacher modeling (playing or singing), and teacher coaching (verbal behavior occurring simultaneous with student performance). The relationship of each of these elements to the total lesson time was expressed in terms of a percentage for each classification. Presentation of academic information by the teacher (1a) was analyzed iurther to determine percentages of teacher talk, modeling, and coaching within the category. Teacher modeling in the form of playing 
or singing which occurred simultaneously with student performance was considered in this instance to be both a modeling presentation as well as a coaching presentation.

Total times were also observed and recorded in the categories of student performance $(2 p)$ and student verbal response (2v). Results in each of these categories were compared to total lesson time. Total student response was determined by adding student performance and student verbal response times, and total student response time was then compared to total lesson time. A ratio of student performance (2p) to student verbal response ( $2 v$ ) was also determined by comparing each to the total student response time.

Teacher reinforcements were analyzed for time spent within the following categories: specific approvals (3as), specific disapprovals ( $3 \mathrm{ds}$ ), non-specific approvals ( $3 a n$ ), and non-specific disapprovals ( $3 \mathrm{dn}$ ).

Total time spent in all categories of teacher reinforcement was also observed and compared to total lesson time.

Total time spent in teacher talk was calculated by adding total time of all teacher presentations (1) to teacher reinforcements (3), less the time spent in teacher modeling. Results were compared to total lesson time in this category as well.

Finally, time spent in social conversation was determined by adding observed time spent in teacher/student interaction (statements from both teacher and student) which was social in nature. "Social" conversations were defined as those which primarily consisted of of $f$-task teacher and student verbal interactions which were removed from the topic of music as well. However, "socia!" interactions were not always exclusively comprised of of f-task statements, since some teacher reinforcement may 
have been observed within the social interaction. Reinforcing comments of this type were considered a part of the "social" conversation if they were observed within this specific off-task interaction. off-task teacher comments which appeared to be verbal mannerisms and/or comments made to themselves were not evaluated as comments which contained social content. Comments of this type were easily determined within the transcripts because they most of ten occurred independent of other offtask statements.

In addition to time analysis of lesson transcripts, frequencies of certain aspects of teacher verbal behavior were also observed and recorded. The number of reinforcing statements made by the teacher were counted and classified, like the time analysis, into specific approvals (3as), specific disapprovals ( $3 d s$ ), non-specific approvals ( $3 a n$ ), and nonspecific disapprovais ( $3 \mathrm{dn}$ ). Ratios were calculated which compared the observed frequencies of each type of reinforcement to total observed reinforcing statemerits within each lesson. Observed frequencies of teacher reinforcements were then compared to time spent in teacher reinforcement to determine the existence of any significant differences between number of comments made and time spent in each group.

Frequencies of teacher-directed patterns were also observed and recorded. Teaching patterns were categorized as either complete/correct, complete/incorrect, or incomplete. (See Figure 1). Complete patterns consisted of a teacher presentation of a musical task ( 1 a or 1d), student response (2), and teacher reinforcement (3). Complete/correct patterns included all three components of the teaching pattern, in addition to being initiated by a specific musical task ( 1 a) and concluding with a specific teacher reinforcement ( 3 as or $3 d s$ ). Complete/incorrect patterns also contained all three components of the complete pattern, but were 
essentially non-specific in either teacher presentation (1d) or teacher reinforcement ( 3 an or $3 \mathrm{dn}$ ). Incomplete patterns were defined as teacherdirected presentations ( 1 a or $1 d$ ) which did not include any type of reinforcement following student response. Patterns which were initiated with teacher comments which were judged to fall into any category other than la or $1 d$ (such as off-task or social statements), as well as studentdirected interactions (patterns beginning with student verbal behavior or performance) were not considered for analysis. 


\section{CHAPTER 3}

\section{Results}

Dependent variables for this study consisted of a measure of time spent within various components of teaching patterns, namely: teacher presentation of academic musical information, modeling, coaching, directive comments, social-behavior comments, social conversation, offtask statements, student performance, student talk, total teacher reinforcing comments, approval/disapproval ratios for reinforcing comments, and specific/non-specific ratios for reinforcing comments. Frequencies of occurrence of reinforcing comments, as well as complete/correct, complete/incorrect, and incomplete teaching patterns also functioned as a dependent measure. Independent variables were student age, student experience, perceived student ability, and teacher experience.

Time spent within each component of the teaching pattern was observed and recorded to the nearest $1 / 100$ th of a second. Total time spent for each componerit within each of the 47 lessons observed was then tabulated, and a percentage comparing observed time spent in each category to total lesson time was calculated. Means were then derived from the results among all 47 lessons. Overall mean percentages for time spent in each of the components of the teaching pattern are presented in Table 1. 
TABLE 1.

MEAN PERCENTAGES OF TIME SPENT IN TEACHING PATTERN COMPONENTS

Teacher Presentation

42.41

Musical Information

37.07

(Modeling)

16.45

(Coaching)

18.71

(Teacher Talk)

64.84

Direction

2.07

Soclal Task

.13

Off-task

3.14

Student Response

47.25

Performance

41.83

Verbal

5.42

Performance/Verbal ratio

$87 / 13$

Teacher Reinforcement

6.24

Approval/Disapproval ratio

$63 / 37$

Specific/Non-specific ratio

$41 / 59$

Non-verbal Behavior

4.10

Total Teacher Talk

41.19

Total Social Interaction

1.74

Results indicated that overall time spent in the three basic teaching pattern components was divided primarily between teacher presentation (42.41\%) and student participation (47.25\%), with a relatively small percentage of overall time spent in teacher reinforcement (6.24\%). Total time spent in teacher talk. was calculated by adding total time of ali 
teacher presentations (1) to teacher reinforcements (3), less the time spent in teacher modeling. Results exhibited a mean of $41.19 \%$ of lesson time spent in total teacher talk.

of the total time spent presenting academic musical information, the method of presentation employed by subjects appeared to have occurred primarily in the form of academic teacher talk (64.84\%), with much smaller percentages in both teacher modeling (16.45\%) and teacher coaching (18.70\%). The majority of time spent in student participation was in the area of student performance, revealing $41.83 \%$ of the total lesson time, or $87 \%$ of the total time spent in student participation. Teacher reinforcernents were primarily approving in nature $63 \%$ of all reinforcement time), but were also essentially non-specific (59\% of all reinforcement time). Teachers spent relatively little time giving directions (2.07\%), making social task presentations (.13\%), making offtask statements (3.14\%), and involving the student in social interaction $(1.74 \%)$.

Mean percentages reflecting time spent in each component of the teaching pattern were also evaluated by student age, student experience, and perceived ability of the student (see Table 2). Subsequent ANOVAs which compared student age, student experience, and perceived student ability refer to the means reported in this table. 
TABLE 2.

MEAN PERCENTAGES OF TIME SPENT IN TEACHING PATTERN COMPONENTS BY STUDENT AGE, EXPERIENCE AND PERCEIVED ABILITY

\begin{tabular}{|c|c|c|c|c|c|c|}
\hline & \multicolumn{2}{|c|}{ Age } & Exper & ience & \multicolumn{2}{|c|}{ Perceived } \\
\hline & $<11$ & $>11$ & «3.5 yrs. & $>3.5$ yrs. & Avg & Better \\
\hline Teacher Presentation (Total) & 47.23 & 37.41 & 44.83 & 38.52 & 44.43 & 41.03 \\
\hline Musical Information & 41.73 & 32.21 & 39.49 & 33.17 & 38.34 & 36.20 \\
\hline (Modeling) & 17.80 & 15.04 & 15.78 & 17.53 & 14.11 & 18.04 \\
\hline (Coaching) & 24.17 & 13.01 & 22.14 & 13.18 & 23.12 & 15.71 \\
\hline (Teacher Talk) & 58.03 & 71.95 & 62.08 & 69.29 & 62.77 & 66.25 \\
\hline Direction & $\underline{2.39}$ & 1.74 & 2.21 & 1.84 & $\underline{2.51}$ & 1.77 \\
\hline Social Task & .18 & 09 & .09 & .21 & .17 & .10 \\
\hline off-task & 2.93 & 3.37 & 3.04 & 3.30 & 3.41 & 2.96 \\
\hline Student Response (Total) & 43.46 & 51.14 & 44.38 & 51.80 & 47.06 & 47.32 \\
\hline Performance & 37.63 & 46.17 & 38.46 & 47.21 & 41.11 & 42.28 \\
\hline Verbal & 5.83 & 4.97 & 5.92 & 4.59 & 5.95 & 5.04 \\
\hline Performance/Verbal ratio & $86 / 14$ & $90 / 10$ & $86 / 14$ & $91 / 9$ & $86 / 14$ & $89 / 11$ \\
\hline Teacher Reinforcement (Total) & 6.18 & 6.31 & 6.21 & 6.29 & 6.33 & 6.18 \\
\hline Approval/Disapproval ratio & $64 / 36$ & $61 / 39$ & $64 / 36$ & $60 / 40$ & $63 / 37$ & $61 / 39$ \\
\hline Specific/Non-specific ratio & $41 / 59$ & $41 / 59$ & $40 / 60$ & $43 / 57$ & $44 / 56$ & $39 / 61$ \\
\hline Non-verbal Behavior & 3.16 & 5.14 & 4.52 & 3.40 & 2.17 & 5.41 \\
\hline (Total Teacher Talk) & 35.61 & 28.69 & 35.24 & 27.29 & 36.65 & 29.24 \\
\hline (Total Social Interaction) & 1.19 & 2.32 & 1.87 & 1.53 & 2.37 & 1.31 \\
\hline
\end{tabular}

Sianificant at 05 
Analysis of variance revealed a significant difference between younger and older students in the area of time spent by the teacher in the presentation of musical information: $F(1,45)=9.59, p<.05$ (see Table 3 ). Students younger than 11 years- of-age received significantly more musical information than students 11 years-or-age or older.

TABLE 3.

Analysis of Variance for Teacher Presentation of Musical Information Comparing Younger and Older Students

\begin{tabular}{llcccc} 
Source & df & Sum of Squares & Mean Square & $F$ & $D$ \\
\hline Students & 1 & 1063.00 & 1063.00 & 9.59 & .003 \\
Within & 45 & 4988.98 & 110.87 & & \\
Total & 46 & 6051.97 & & & \\
& & & & & \\
\hline
\end{tabular}

of all musical information given to students, younger students received significantly more information in the form of coaching by the teacher (i.e., instruction given while the student was performing). A oneway ANOVA exhibited significant differences between younger and older student with respect to teacher coaching: $F(1,45)=6.88, p<.05$ (see Table 4). 
TABLE 4.

Analysis of Variance for Teacher Coaching Comparing Younger and Older Students

\begin{tabular}{llcccr} 
Source & df & Sum of Squares & Mean Square & $F$ & $p$ \\
Students & 1 & 1467.50 & 1467.50 & 6.88 & .01 \\
Within & 45 & 9601.72 & 213.37 & & \\
Total & 46 & 11069.21 & & & \\
& & & & & \\
\hline
\end{tabular}

In addition to differences between younger and older students in the area of coaching, an analysis of variance revealed a significant difference between student ages with respect to percentages of time spent in academic teacher talk: $F(1,45)=6.76, p<.05$ (see Table 5). In this case, older students received significantly more musical information in the form of teacher talk than did younger students.

TABLE 5.

Analysis of Variance for Academic Teacher Talk Comparing Younger and older Students

$\begin{array}{llcccr}\text { Source } & \text { df } & \text { Sum of Squares } & \text { Mean Square } & F & \text { p } \\ \text { Students } & 1 & 2274.42 & 2274.42 & 6.76 & .01 \\ \text { Within } & 45 & 15140.35 & 336.45 & & \\ \text { Total } & 46 & 17414.76 & & & \end{array}$


Further use of ANOVA indicated that younger students received significantly more direction from teachers than older students: $F(1,45)=$ $7.78, p<.05$ (see Table 6).

TABLE 6.

Analysis of Variance for Teacher Direction Comparing Younger and Older $\underline{\text { Students }}$

\begin{tabular}{llcccc} 
Source & df & Sum of Squares & Mean Square & $F$ & $p$ \\
\hline Students & 1 & 5.06 & 5.06 & 7.78 & .008 \\
Within & 45 & 29.23 & .65 & & \\
Total & 46 & 34.29 & & & \\
& & & & & \\
\hline
\end{tabular}

Also in the area of percentage of time spent in teacher direction, results showed that those students perceived as "average" by their teachers received significantly more directive comments than those students perceived as "better", $F(1,45)=10.02, p<.05$ (see Table 7). 
TABLE 7.

Analysis of Variance for Teacher Direction Comparing "Average" and "Better" Students

\begin{tabular}{llcccc} 
Source & df & Sum of Squares & Mean Square & $F$ & $p$ \\
Students & 1 & 6.24 & 6.24 & 10.02 & .003 \\
Within & 45 & 28.05 & .62 & & \\
Total & 46 & 34.29 & & & \\
& & & & & \\
\hline
\end{tabular}

Furthermore, an analysis of variance indicated a significant difference between younger and older students with respect to the total time spent in all teacher talk (i.e., total time spent in teacher reinforcement plus percentage of total lesson time spent in coaching, academic teacher talk, direction, social task, and off-task comments): $F(1,45)=5.89, p<.05$ (see Table 8). Younger students heard significantly more teacher talk in their lessons than older students.

TABLE 8.

Analysis of Variance for Total Teacher Talk Comparing Younger and Older Students

\begin{tabular}{llcccc} 
Source & df & Sum of Squares & Mean Square & $F$ & D \\
Students & 1 & 495.27 & 495.27 & 5.89 & .02 \\
Within & 45 & 3786.57 & 84.15 & & \\
Total & 46 & 4281.84 & & & \\
& & & & & \\
\hline
\end{tabular}


Results also indicated that older students spent a significantly nigher percentage of time in overall participation in the the lesson than did younger students: $F(1,45)=5.60, p<.05$ (see Table 9).

TABLE 9.

Analysis of Variance for Total Student Participation Comparing Younger and Older Students

\begin{tabular}{llcccr} 
Source & df & Sum of Squares & Mean Square & $F$ & $p$ \\
Students & 1 & 679.10 & 679.10 & 5.60 & .02 \\
Within & 45 & 5460.50 & 121.34 & & \\
Total & 46 & 6139.60 & & & \\
& & & & & \\
\hline
\end{tabular}

Differences in participation between older and younger students appeared to take place in the area of student performance. Analysis of variance exhibited a significant difference between older and younger students in the area of performance: $F(1,45)=6.26, p<.05$ (see Table 10). older students spent significantly more time in performance than younger students. 
TABLE 10.

Analysis of Variance for Student Performance Comparing Younger and older Students

\begin{tabular}{llcccr} 
Source & df & Sum of Squares & Mean Square & $F$ & D \\
Students & 1 & 857.23 & 857.23 & 6.26 & .02 \\
Within & 45 & 6163.42 & 136.97 & & \\
Total & 46 & 7020.66 & & & \\
& & & & & \\
\hline
\end{tabular}

Student experience also appeared to be a factor in determining time spent in student participation. An ANOVA revealed that students with more than 3.5 years of experience participated significantly more than students with less than 3.5 years of experience: $F(1,45)=4.88, p<.05$ (see Table 11).

TABLE 11.

Analysis of Variance for Total Student Participation Comparing LessExperienced and More-Experienced Students

\begin{tabular}{llcccr} 
Source & df & Sum of Squares & Mean Square & $F$ & p \\
Students & 1 & 600.73 & 600.73 & 4.88 & .03 \\
Within & 45 & 5538.87 & 123.09 & & \\
Total & 46 & 6139.60 & & & \\
& & & & & \\
\hline
\end{tabular}


Again, results of an analysis of variance indicated significant differences between more-experienced and less-experienced students in the area of student performance: $F(1,45)=6.21, p<.05$ (see Table 12). Students with more experience spent significantly more time in performance than less-experienced students.

TABLE 12.

Analysis of Variance for Student Performance Comparing Less-Experienced and More-Experienced Students

\begin{tabular}{llcccc} 
Source & df & Sum of Squares & Mean Square & $F$ & D \\
\hline Students & 1 & 851.38 & 851.38 & 6.21 & .02 \\
Within & 45 & 6169.28 & 137.10 & & \\
Total & 46 & 7020.66 & & & \\
& & & & & \\
\hline
\end{tabular}

No significant main effects were evident when considering the variable of teacher experience within the components listed in Table 2 $(p>05)$. However, a closer examination of approvals and disapprovals, both specific and non-specific revealed significant differences in the area of teacher experience, particularly as it related to other variables in the current study. A two-factor ANOVA exhibited a significant interaction between teacher experience and student experience on overall approvals: $F(1,43)=10.45, p<.05$ (see Table 13). There were no significant differences for either of the main factors of teacher experience or student experience. 
TABLE 13.

Analysis of Variance for Overall Approvals Comparing Teacher Experience and Student Experience

\begin{tabular}{lccccc} 
Source & df & Sum of Squares & Mean Square & $F$ & $p$ \\
\hline Teacher (T) & 1 & 221.28 & 221.28 & 1.06 & .31 \\
Student (S) & 1 & 41.34 & 41.34 & .20 & .66 \\
TXS & 1 & 2172.74 & 2172.74 & 10.45 & .002 \\
Residual & 43 & 8938.08 & 207.86 & & \\
& & & & & \\
\hline
\end{tabular}

Results showed that teachers with less than 18.5 years of teaching experience were more approving with those students who had more than 3.5 years of experience than they were with those who had less than 3.5 years of experience. Alternately, teachers with more than 18.5 years of teaching experience were less approving to students with more than 3.5 years of experience than they were to students with less experience (see Figure 2). 
FIGURE 2.

\section{EFFECT OF TEACHER EXPERIENCE AND STUDENT EXPERIENCE}

ON PERCENTAGE OF OYERALL APPROVALS

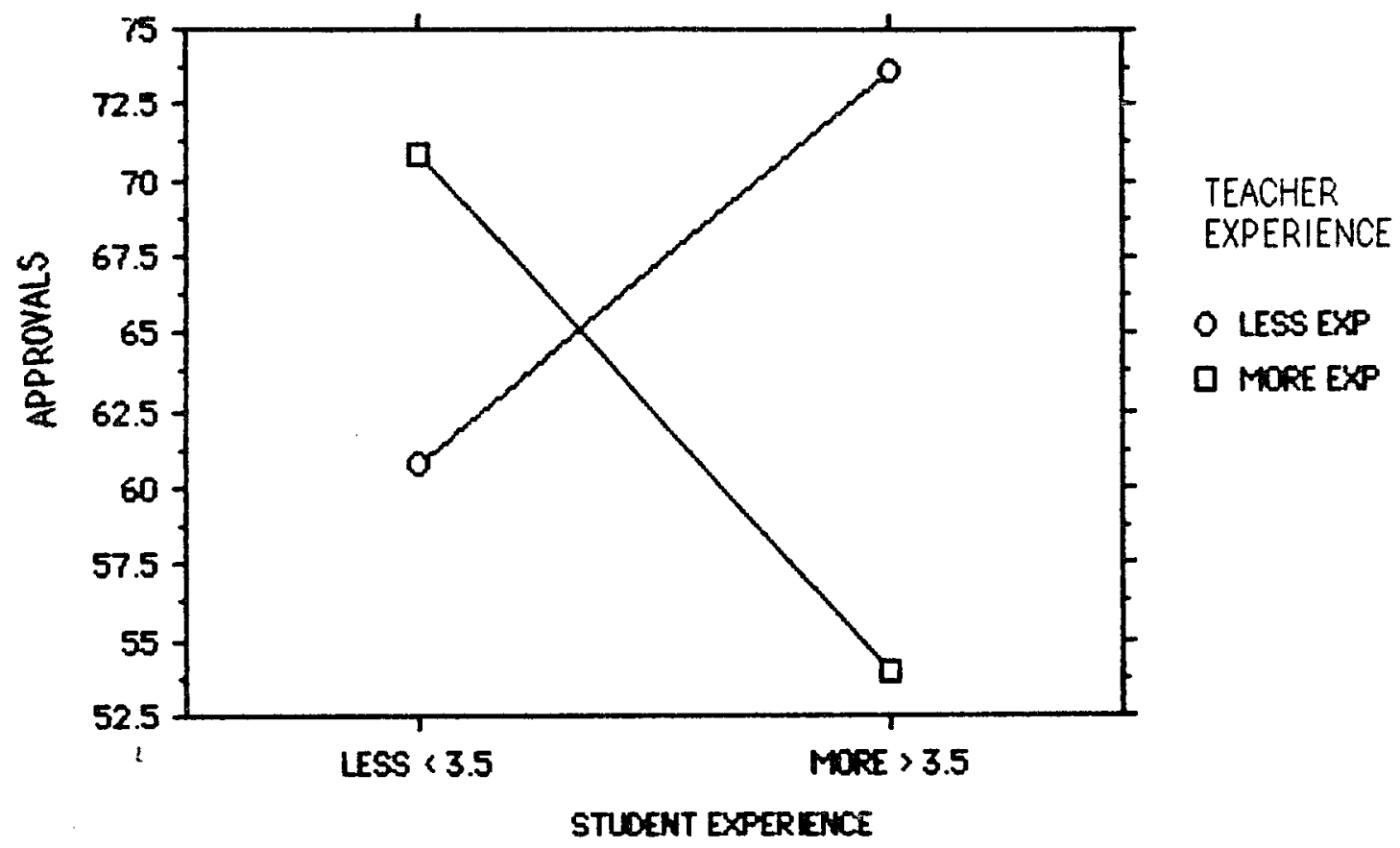

A two-factor ANOVA revealed a significant interaction between teacher experience and student experience on overall disapprovals: $F(1,43)=10.52, p<.05$ (see Table 14). More-experienced teachers expressed a higher percentage of verbal disapprovals than lessexperienced teachers when both were dealing with more-experienced students. The opposite was true for less-experienced students (see Figure 3). No significant main effects were evident. 
TABLE 14.

Analysis of Variance for Overall Disapprovals Comparing Teacher

Experience and Student Experience

\begin{tabular}{lccccc} 
Source & df & Sum of Squares & Mean Square & $F$ & $D$ \\
Teacher (T) & 1 & 217.40 & 217.40 & 1.05 & .31 \\
Student (S) & 1 & 39.65 & 39.65 & .19 & .66 \\
TXS & 1 & 2185.71 & 2185.71 & 10.52 & .002 \\
Residual & 43 & 8934.19 & 207.77 & & \\
\hline
\end{tabular}

FIGURE 3.

EFFECT OF TEACHER EXPERIENCE AND STUDENT EXPERIENCE ON PERCENTAGE OF OVERALL DISAPPROVALS

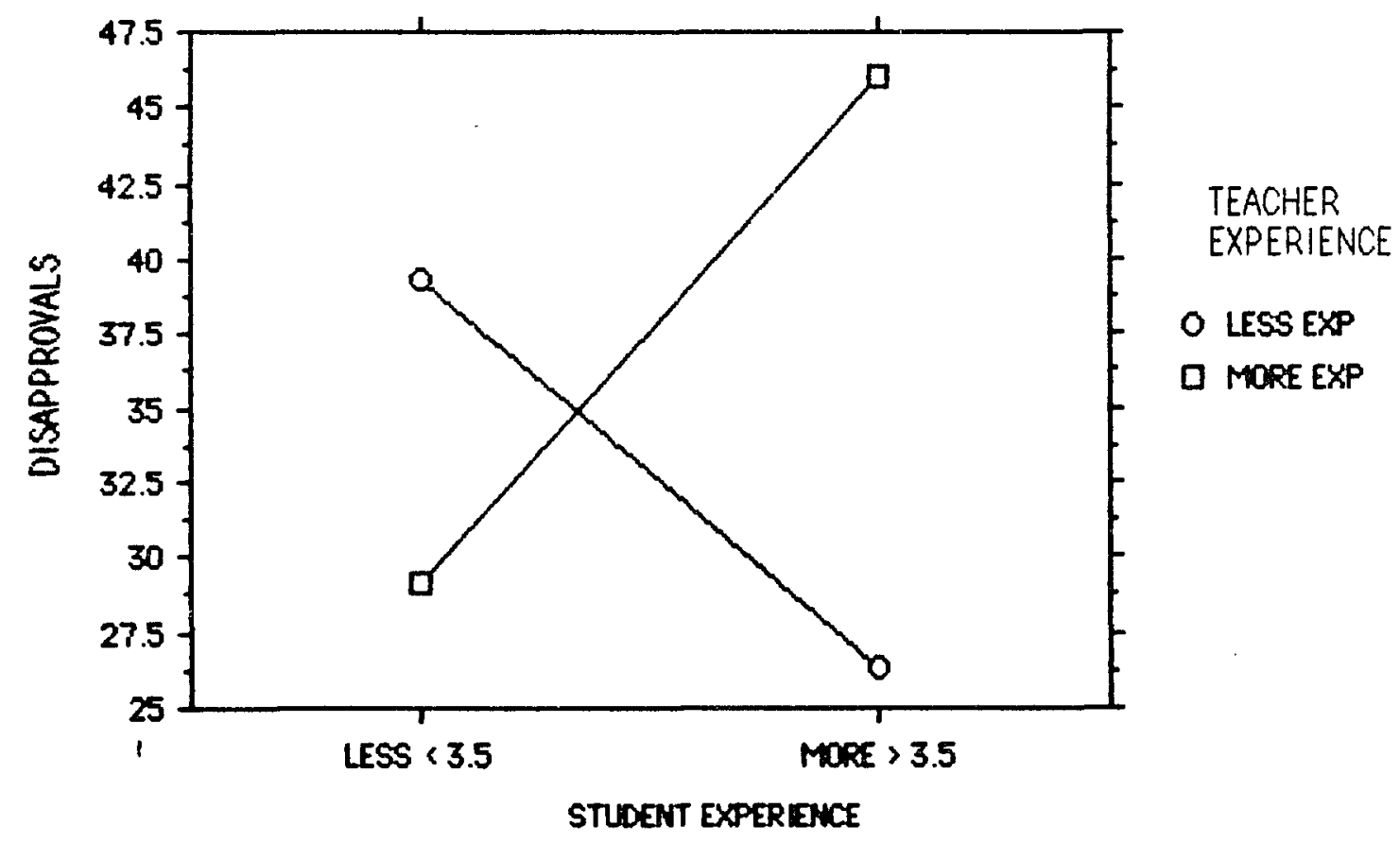


A two-factor ANOVA indicated a significant main effect regarding teacher experience and specific verbal approvals: $F(1,43)=8.17$, p. $<.05$ (see Table 15). Teachers with less than 18.5 years of teaching experience spent a significantly greater percentage of time in specific, approving verbal reinforcement (15.68\%) than their more-experienced colleagues (10.27\%). No main effects were evident in the area of student experience, and no significant interactions were found.

TABLE 15

Analysis of Variance for Specific Verbal Approvals Comparing Teacher Experience and Student Experience

\begin{tabular}{lccccc} 
Source & df & Sum of Squares & Mean Square & $F$ & $D$ \\
\hline Teacher (T) & 1 & 441.21 & 441.21 & 8.17 & .007 \\
Student (S) & 1 & 41.13 & 41.13 & .76 & .39 \\
TXS & 1 & 97.06 & 97.06 & 1.80 & .19 \\
Residual & 43 & 2320.79 & 53.97 & & \\
\end{tabular}

A two-factor ANOVA showed a significant interaction between teacher experience and student experience on non-specific verbal approvals: $F(1.43)=6.86, p<.05$ (see Table 16). There were no significant differences for either of the main factors of teacher experience or student experience. 
TABLE 16.

Analysis of Variance for Non-Specific Verbal Approvals Comparing

Teacher Experience and Student Experience

\begin{tabular}{lccccc} 
Source & df & Sum of Squares & Mean Square & $F$ & $D$ \\
\hline Teacher (T) & 1 & 37.57 & 37.57 & .19 & .66 \\
Student (S) & 1 & 165.15 & 165.15 & .84 & .37 \\
TXS & 1 & 1352.11 & 1352.11 & 6.86 & .01 \\
Residual & 43 & 8477.39 & 197.15 & & \\
& & & & & \\
\hline
\end{tabular}

Teachers with more than 18.5 years of experience employed more nonspecific approvals with their less-experienced students than teachers with fewer years of experience used with their students of less experience. On the other hand, teachers with less than 18.5 years of experience used more non-specific approvals with their more-experienced students than more-experienced teachers used with their students of more experience (see Figure 4). 
FIGURE 4.

EFFECT OF TEACHER EXPERIENCE AND STUDENT EXPERIENCE

ON PERCENTAGE OF NON-SPECIFIC VERBAL APPR.OVALS

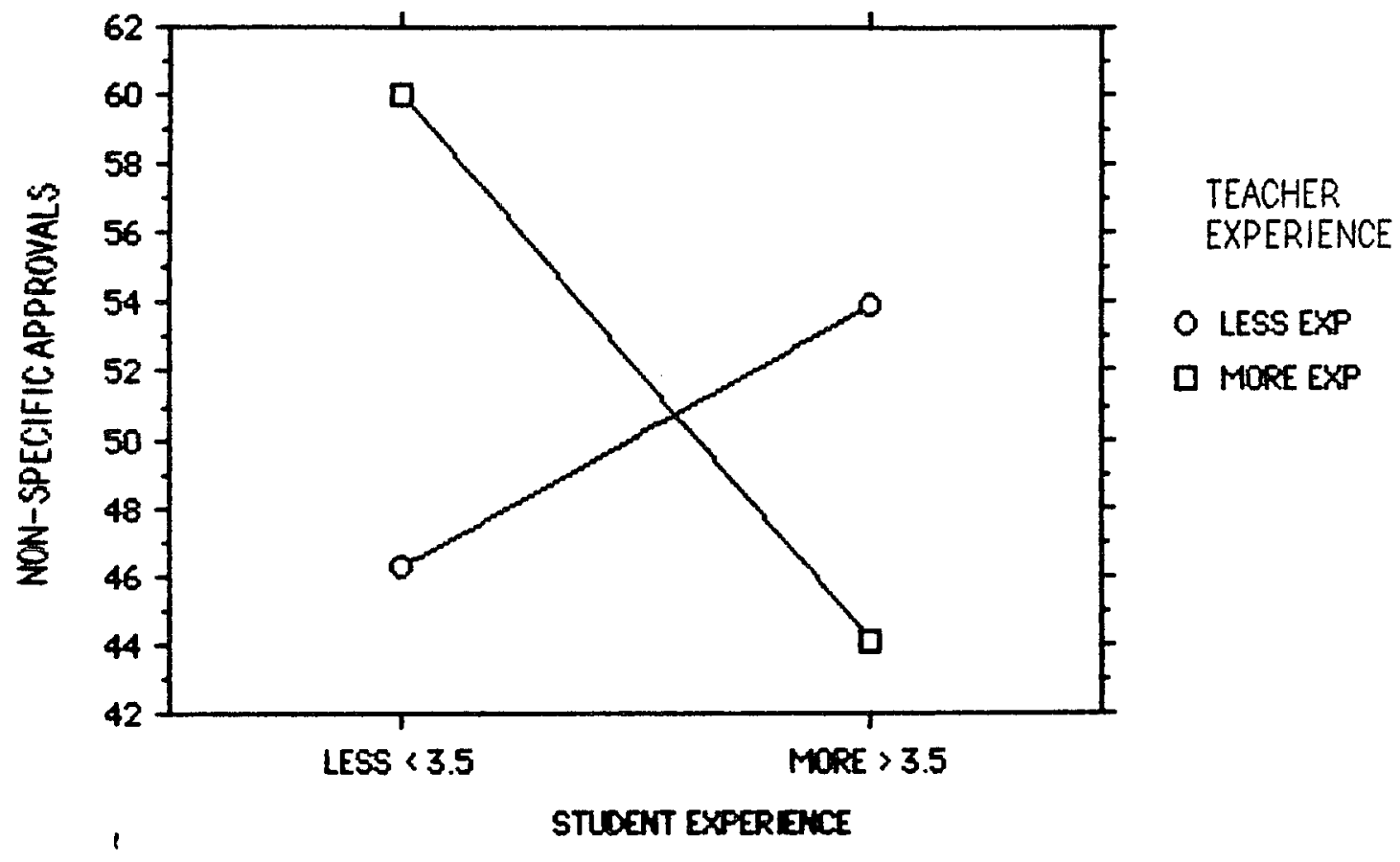

In contrast, a two-factor ANOVA revealed a significant interaction between teacher experience and student experience on non-specific disapprovals: $F(1,43)=5.10, p<.05$ (see Table 17). Again, there were no significant differences for the main factors of teacher experience and student experience. 
TABLE 17.

Analysis of Variance for Non-Specific Verbal Disapprovals Comparing Teacher Experience and Student Experience

\begin{tabular}{lcrrrr} 
Source & df & Sum of Squares & Mean Square & $F$ & $D$ \\
\hline Teacher (T) & 1 & 73.31 & 73.31 & 1.36 & .25 \\
Student (S) & 1 & .07 & .07 & .001 & .97 \\
TXS & 1 & 274.34 & 274.34 & 5.10 & .03 \\
Residual & 43 & 2313.20 & 53.80 & & \\
& & & & & \\
\hline
\end{tabular}

Teachers with less experience employed more non-specific verbal disapprovals to their less-experienced students than did more-experienced teachers. On the other hand, teachers with more experience expressed more non-specific verbal disapprovals to their more-experienced students than did less-experienced teachers (see Figure 5). 
FIGURE 5.

EFFECT OF TEACHER EXPERIENCE AND STUDENT EXPERIENCE

ON PERCENTAGE OF NON-SPECIFIC VERBAL DISAPPROVALS

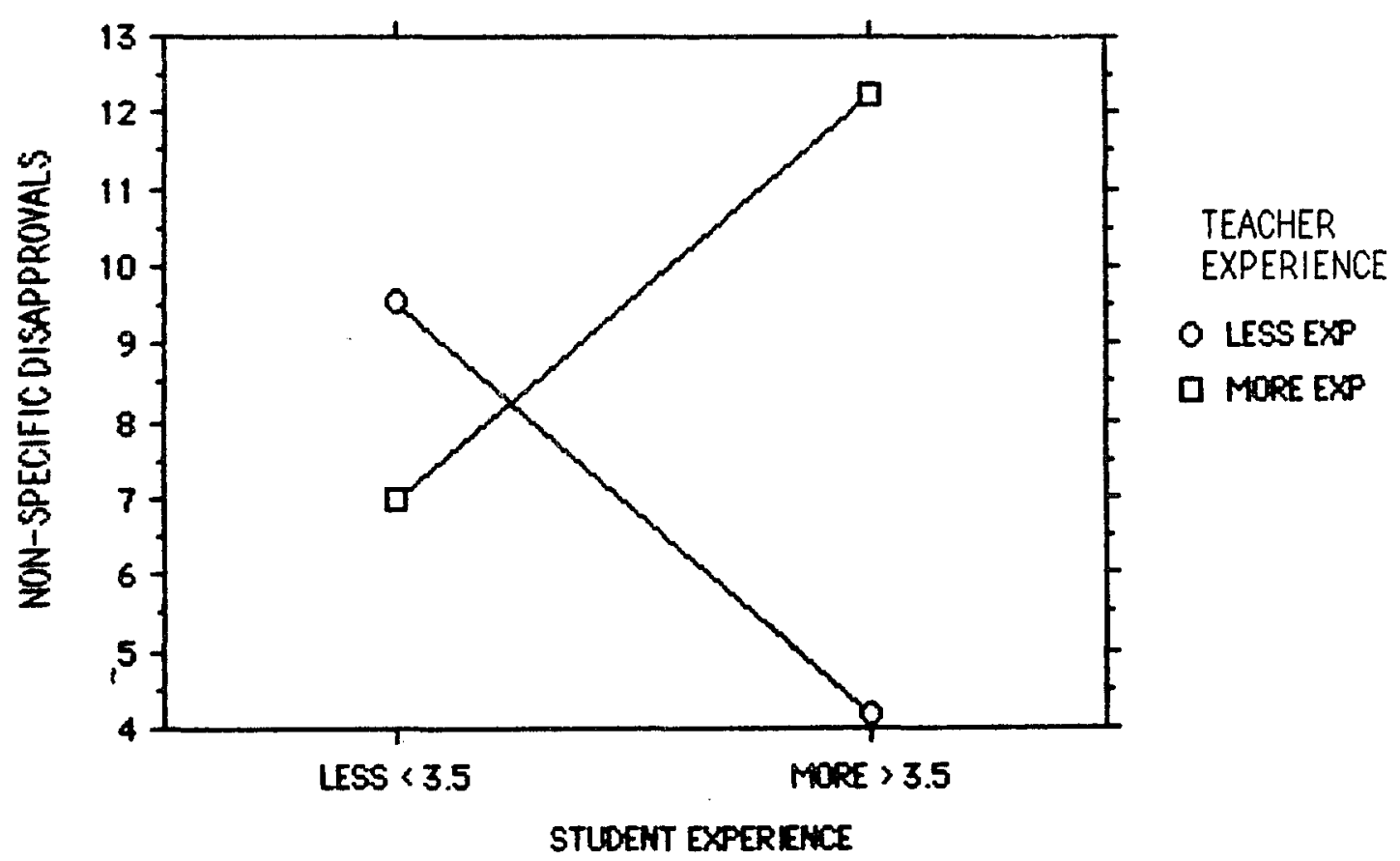

Another two-factor ANOVA exhibited significant interaction between teacher experience and student experience in the area of specific verbal disapprovals as well: $F(1,43)=5.80 p<.05$ (see Table 18). There were no significant differences between either of the main factors of teacher experience or student experience. 
TABLE 18.

Analysis of Variance for Specific Verbal Disapprovals Comparing Teacher Experience and Student Experience

\begin{tabular}{lccccc} 
Source & df & Sum of Squares & Mean Square & $F$ & $p$ \\
\hline Teacher (T) & 1 & 38.09 & 38.09 & .24 & .63 \\
Student (S) & 1 & 43.05 & 43.05 & .27 & .60 \\
TXS & 1 & 911.98 & 911.98 & 5.80 & .02 \\
Residual & 43 & 6761.71 & 157.25 & & \\
& & & & & \\
\hline
\end{tabular}

Teachers with fewer years of teaching experience were more disapproving with specific comments to their less-experienced students than teachers with more experience were to their students of less experience. But the opposite was the case with respect to more-experienced students. That is, teachers with more experience verbalized more specific disapprovals to more-experienced students than less-experienced teachers did with their more-experienced students (see Figure 6). 
FIGURE 6.

EFFECT OF TEACHER EXPERIENCE AND STUDENT EXPERIENCE

ONPERCENTAGE OF SPECIFIC YERBAL DISAPPROVALS

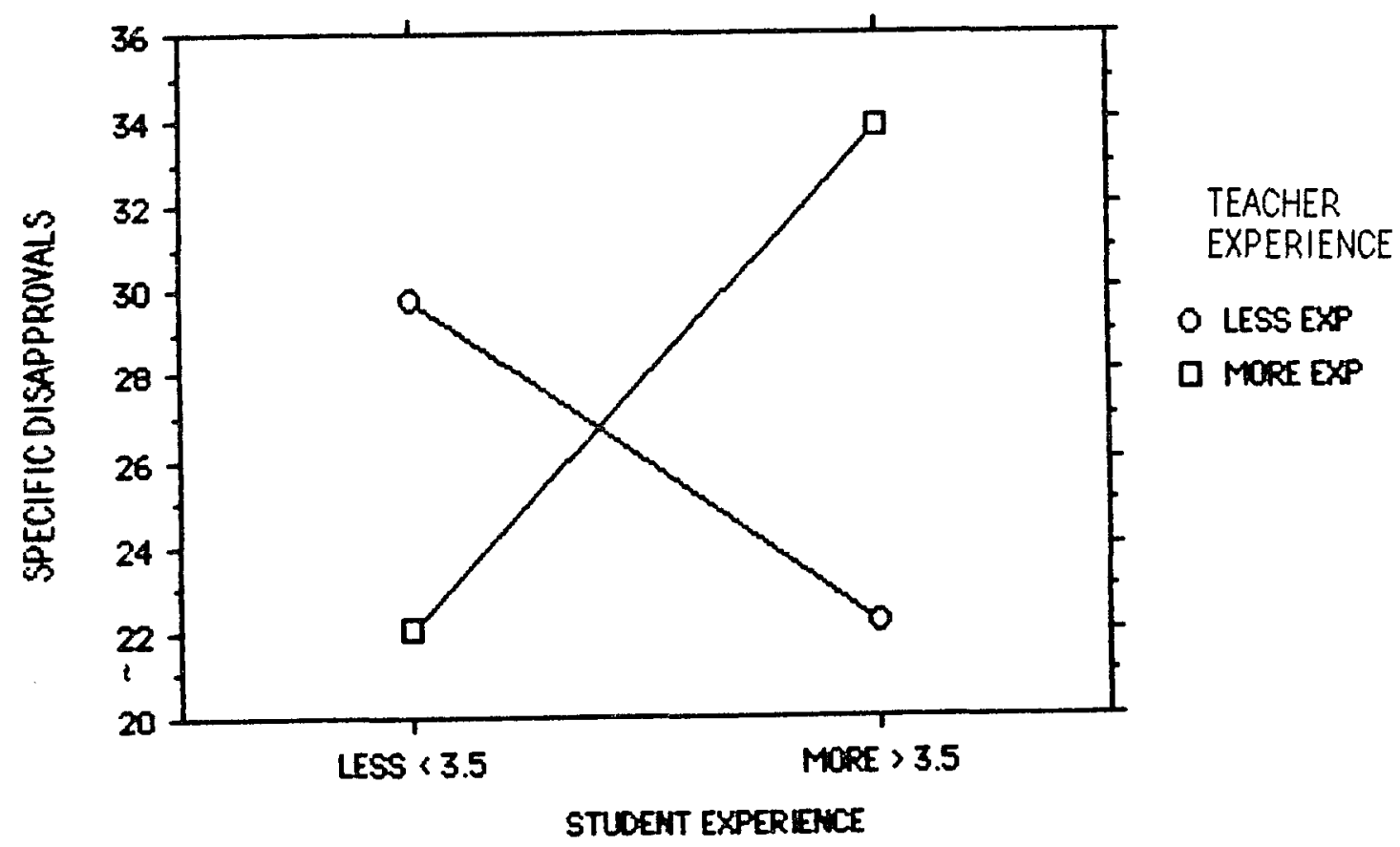

A comparison was made between the mean percentages obtained from observed frequencies of verbal reinforcement and the means calculated from time spent by teachers in the same category. Paired $\underline{t}$-tests were conducted to determine significant differences between the groups.

Results indicated significant differences between the frequency of occurrence and time spent in the categories of non-specific approvals, $\underline{t}(46)=21.62, p<.05$; specific approvals, $\underline{t}(46)=-6.85, p<.05$; and specific disapprovals, $\underline{t}(46)=-14.86, p<.05$. No significant difference appeared between percentage of observed frequencies and percentage of time spent in the area of non-specific disapprovals ( $p>05)$. An 
examination of the means indicated that the percentage of time spent in non-specific approvals was significantly less than the frequency of them. on the other hand, the percentage of time spent in both specific approvals and specific disapprovals was significantly greater than the frequency of them (see Table 19).

TABLE 19.

COMPARISON OF OVERALL MEAN PERCENTAGES OF FREQUENCY AND TIME SPENT IN YERBALL PEINFORCEMENT

\begin{tabular}{lcccc} 
& \multicolumn{2}{c}{ Approvals } & \multicolumn{2}{c}{ Disapprovals } \\
& Specific* & Non-specific* & Specific* & Non-specific \\
Frequency & 8.49 & 67.21 & 14.83 & 8.45 \\
Time Spent & 13.26 & 49.32 & 28.39 & 9.06
\end{tabular}

*Significant at .05

Further investigation into other components of teaching patterns revealed a significant interaction between the factors of teacher experience and percelved student ablitty in the area of student verbalization: $F(1,43)=4.75, p<.05$ (see Table 20). There were no significant differences for either of the main factors of teacher experience or perceived student ability. 
TABLE 20.

Analysis of Variance for Student Verbalization Comparing Teacher Experience and Percelved Student Abllity

\begin{tabular}{lccccc} 
Source & df & Sum of Squares & Mean Square & $F$ & D \\
\hline Teacher (T) & 1 & 28.06 & 28.06 & .38 & .54 \\
Ability (A) & 1 & 80.08 & 80.08 & 1.08 & .30 \\
TXA & 1 & 352.73 & 352.73 & 4.75 & .03 \\
Residual & 43 & 3194.24 & 74.28 & & \\
\hline
\end{tabular}

Results indicated that time spent in student verbal behavior was higher among students perceived as "average" when they were with a moreexperienced teacher. "Better" students verbalized for a smaller percentage of the total lesson time with more experienced teachers, while "better" students verbalized more with less-experienced teachers (see Figure 7). 
FIGURE 7.

EFFECT OF TEACHER EXPERIENCE AND PERCEIVED STUDENT ABILITY

ON STUDENT VERBAL. BEHAVIOR WHEN COMPARED TO TOTAL STUDENT PARTICIPATION

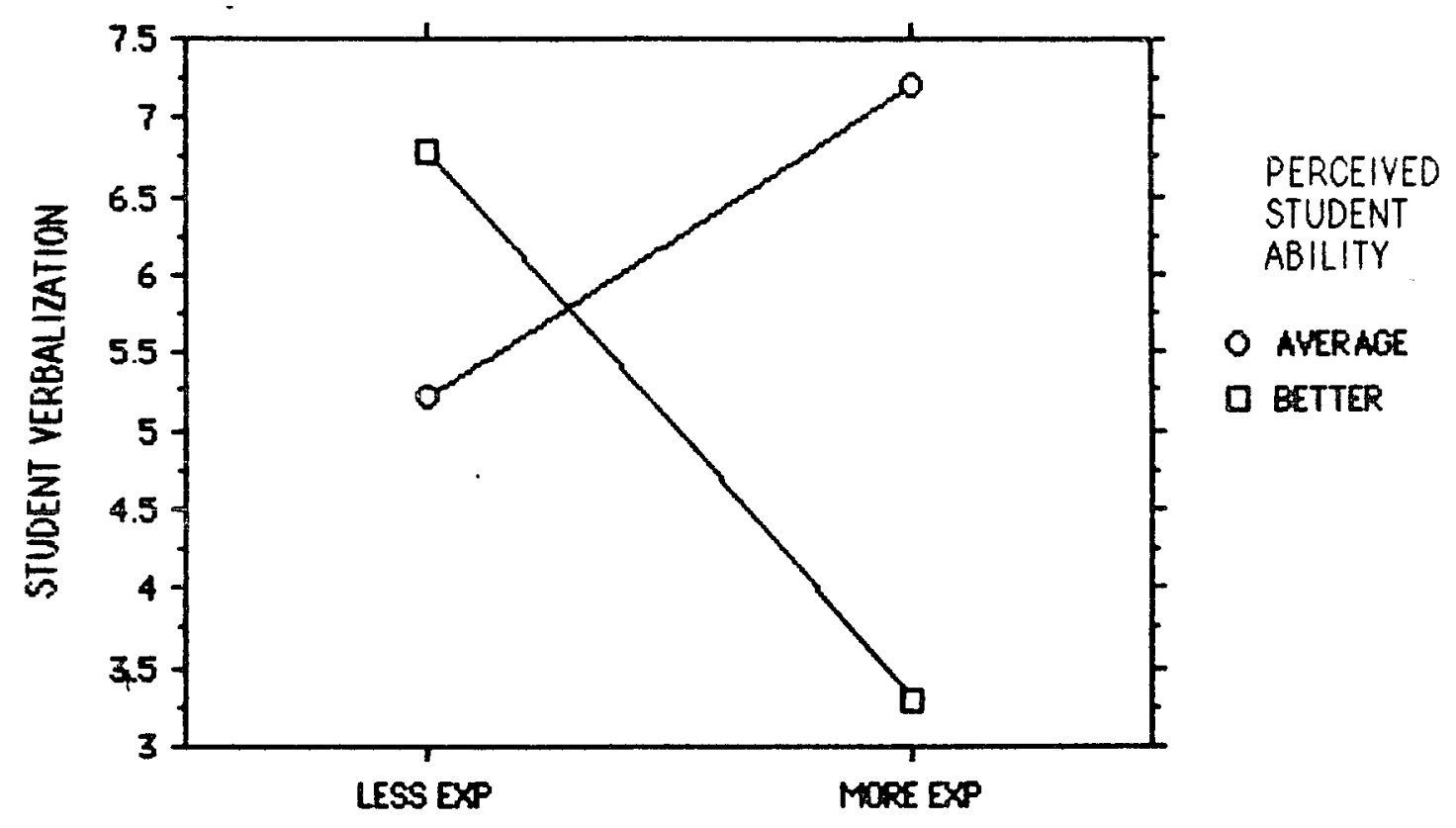

TEACHER EXPER EMCE

In contrast, results from an additional two-factor ANOVA indicated a significant interaction between teacher experience and perceived student ability on the percentage of time spent in student performance when compared to total student participation: $F(1,43)=4.75, p<.05$ (see Table 21). Again, there were no significant differences for either of the main factors of teacher experience or perceived student ability. 
TABLE 21.

Analysis of Variance for Student Performance Comparing Teacher

Experlence and Perceived Student Ability

\begin{tabular}{lccccc} 
Source & df & Sum of Squares & Mean Square & $F$ & D \\
\hline Teacher (T) & 1 & 27.86 & 27.86 & .38 & .54 \\
Ability (A) & 1 & 82.84 & 82.84 & 1.12 & .29 \\
TXA & 1 & 349.56 & 349.56 & 4.75 & .03 \\
Residual & 43 & 3167.58 & 73.66 & & \\
& & & & & \\
\hline
\end{tabular}

"Better" students evidently performed more than their "average" peers when they were both with a more-experienced teacher. On the other hand, students perceived as "better" performed less than "average" students when both were with a less-experienced teacher (see Figure 8 ). 
FIGURE 8.

EFFECT OF TEACHER EXPERIENCE AND PERCEIVED STUDENT ABILITY

ON STUDENT PERFORMANCE WHEN COMPARED TO TOTAL STUDENT PARTICIPATION

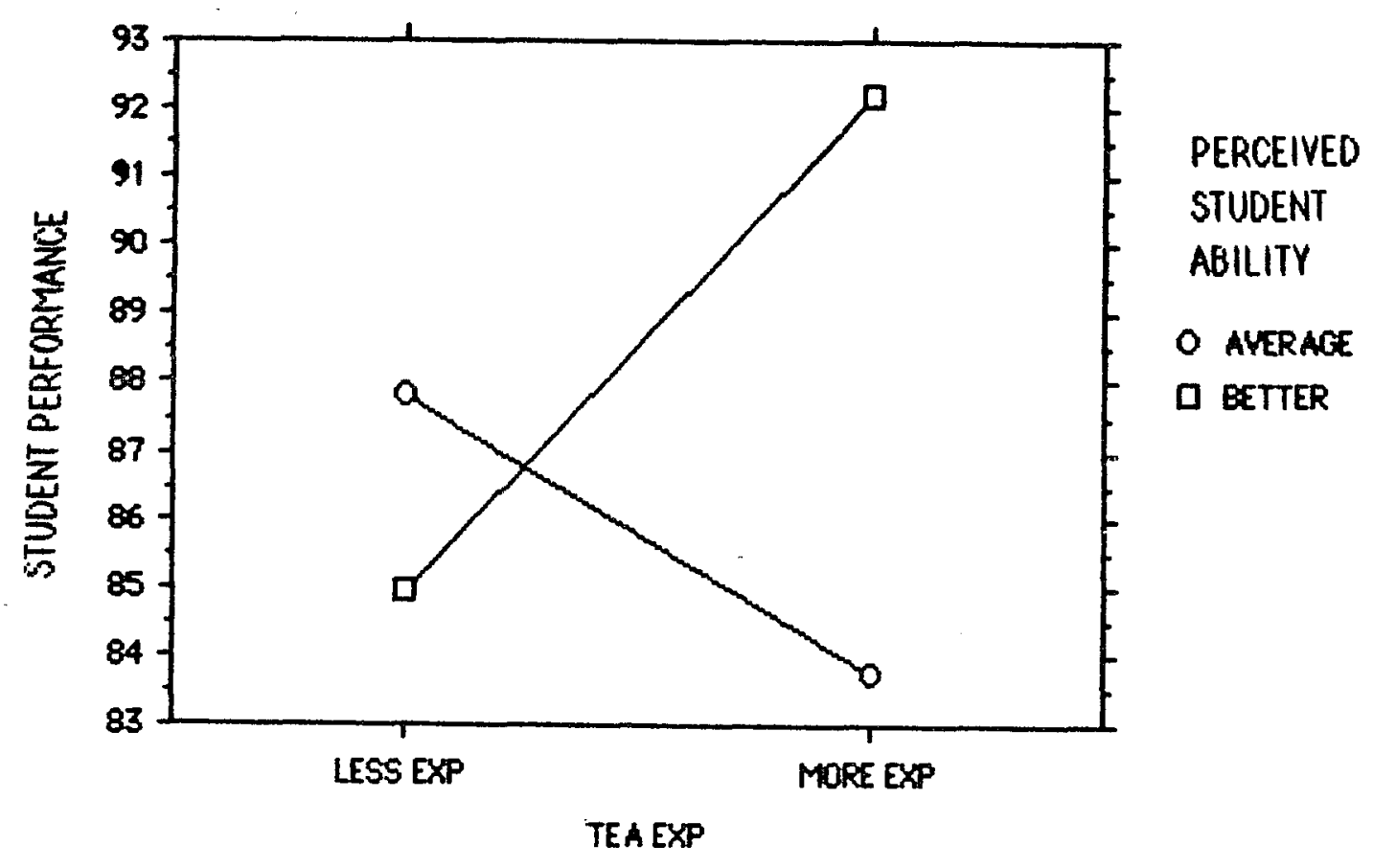

In addition to the examination of the various components of teaching patterns, the total number of teaching patterns within each lesson was determined as well. Percentages of complete/correct, complete/incorrect, and incomplete patterns were calculated by comparing observed frequencies of each of the three categories to the total number of patterns observed in each lesson. Means were obtained from the percentage of frequencies observed among all 47 lessons in the areas of complete/correct, complete/incorrect, and incomplete teaching patterns. An ANOVA revealed significant differences among the means of 
the three groups: $F(2,138)=283.31, p<.05$ (see Table 22).

TABLE 22.

Analysis of Variance for Sequential Patterns Comparing Percentages of Complete/Correct, Complete/Incorrect, and incomplete Patterns

\begin{tabular}{lccccc} 
Source & df & Sum of Squares & Mean Square & $F$ & $D$ \\
\hline Patterns & 2 & 34919.99 & 17460.00 & 283.31 & .0001 \\
Within & 138 & 8504.85 & 61.63 & & \\
Total & 140 & 43424.84 & & & \\
& & & & & \\
\hline
\end{tabular}

Post-hoc comparisons using the Fisher PLSD test revealed significant differences between the means for complete/correct patterns and both complete/incorrect and incomplete patterns $(p<.05)$. There was no significant difference between the means of complete/incorrect and incomplete patterns ( $p>05$ ) (see Table 23).

TABLE 23.

Comparison of Means for Complete/Correct, Complete/Incorrect, and Incomplete Patterns

Complete/Correct Complete/Incorrect Incorrect 11.32 $41.58-$ n.s. $\quad 47.13$

Teaching patterns were also analyzed in relation to the variables of student age, student experience, perceived student ability, and teacher 
experience. No significant differences were found among the groups in relation to those particular factors being investigated $(p>05)$.

A Spearman Rank Correlation was employed to test for correlation between teacher values as expressed on the post-hoc questionnaire and observed behaviors in the areas of social interaction, total time spent in the presentation of academic information, teacher talk, coaching, modeling, total student performance, total teacher reinforcement, ratio of approving/disapproving comments, and percentage of specific reinforcements. Results indicated little, if any correlation between expressed teacher values and observed behaviors (see Table 24) coefficients ranged from .18 to -31 . The highest positive correlation occurred in the area of academic teacher talk (.18), while the highest negative correlation occurred in the area of specific verbal reinforcement $(-31)$. None of the correlation coefficients were significant. 
TABLE 24.

SPEARMAN RANK CORRELATION COEFFICIENTS COMPARING EXPRESSED TEACHER VALUES TO OBSERVED TEACHER BEHAVIORS

Rho

Social Interaction

.06

Total Academic Information

$-.04$

Teacher Talk

.18

Coaching

$-.02$

Modeling

.01

Student Participation

.16

Teacher Reinforcement

$-.10$

Approving Comments

.03

Disapproving Comments

.03

Specific Reinforcements

$-.31$ 
CHAPTER 4

Discussion

The purpose of this study was to observe the verbal behavior of the independent piano teacher in relation to components of teaching patterns established through prior research. Teachers $(N=25)$ were asked to audiotape the individual piano lessons of two different students. Students were to be selected on the basis of age and perceived ability. Teachers were encouraged to allow the lessons to flow as normally as possible, in order to approximate the "typical" piano lesson. Transcripts were developed from the completed audiotapes, and were then examined by time and frequency for the presence of various components of teaching patterns.

Results revealed the variable of student age as a primary factor in the determination of differences in overall time spent within several categories of the private piano lesson. Teachers spent more time talking to younger students, while allowing older students to spend more time of each lesson in performance. These results support those reported by Kostka (1984). In addition to these findings, results also indicated that younger students received significantly more musical information than older students. Both younger and older students received most of their musical information in the form of academic teacher talk. However, when compared to older students, younger pupils apparently received significantly more musical information while they were performing.

An examination of results also indicated that a large percentage of the "typical" piano lesson was spent in student participation, with most of that time spent in student performance. Again, this finding supported the 
results obtained by Kostka (1984). In addition to student age, student. experience appeared to be a significant factor overall when examining the amount of time spent performing. This seems logical, since students with more experience are likely to be playing longer pieces, therefore requiring more of the lesson time in order to perform.

In addition to the results mentioned above, the significant interaction evidenced between the variables of teacher experience and perceived student ability suggested an interesting relationship in the area of student participation. Results seemed to indicate that students perceived as "average" spent less time performing than "better" students when both groups were with a more experienced teacher. The inverse to this finding was the indication that "average" students verbalized more than their "better" counterparts when they were with a more experienced teacher.

Along with student participation, a large portion of the individual piano lesson was spent in the presentation of academic musical information. Teacher-talk was by far the most predominant method of teacher presentation, with both modeling and coaching each being employed under $20 \%$ of the time. Teachers in the private lesson setting spent a very smiall portion of the total lesson time giving directions arid making social and off-task statements.

It was interesting to note that perceived student ability was a factor in the amount of time spent by the teacher in giving directions. Results supported the idea that students perceived by their teachers as "average" received significantly more instruction in the form of directions by the teacher. This essentially means that "average" students heard more nonspecific musical task presentation than thase students perceived as "better." It is possible that teachers in this study believed that they had to spend much of the lesson time reviewing assignments which were not practiced adequately by the "average" student, essentially resulting in 
"drilling" passages which would in turn, require directive comments.

It is important to understand that no attempt was made to define the "average" and the "better" student for teachers participating in the study, since there may be many factors other than musical advancement involved in the perception of a student's ability (such as diligence, courtesy, and personality, to name a few). Although musical advancement alone was not suggested as a criteria for determining the "average" and "better" student, most teachers appeared to have selected students primarily on this basis. As a result, many of the students selected for this study and considered to be "average" by their teachers were also younger, less experienced students, while the "better" student may have been simply more musically advanced. Although results revealed no significant interaction between perceived ability and other factors, it is possible that teachers spent much of the time giving directions to the "average" (younger and/or lessexperienced) student in order to establish practice habits and develop kinesthetic response. Results in this area may need to be considered carefully, due to the ambiguity of the terms "average" and "better."

In the category of time spent in reinforcement by the independent piano teacher, overall results indicate that on the average, only $6 \%$ of the total lesson time was spent in verbal reinforcement. This finding supports the results reported by Yarbough and Price (1989) in their observation of band directors, chorai conductors, and college undergraduates. Of all reinforcing comments made in the private piano lesson, the majority (63\%) were approving in nature. However, it should be noted that within every group, more than half of all reinforcing statements were non-specific in nature. Comparison of this finding to that of Yarbrough and Price (1989) seems to suggest that independent piano teachers in the private-lesson setting are generally less specific than other music educators in their responses to student activity. It is 
also important to take note of results which indicated that, next to nonspecific approvals, most of the time spent in reinforcing comments was found in disapprovals which were specific in nature. This supports the results reported by Duke and Madsen (1991).

Because it is not clear whether the number of comments made or the time spent in making comments is more influential in the teaching/learning environment, frequencies of reinforcing comments were observed and recorded in addition to time spent in those areas. Nonspecific approvals occurred most of ten among all types of verbal reinforcement when measured by both frequency and time. However, the frequency of non-specific approvals was observed to be significantly higher than time spent in non-specific approvals, while time spent in specific approvals and disapprovals was significantly higher than frequency counts in these areas. This is not surprising, since specific comments are generaily longer by nature, therefore resulting in an increase in time spent. It should be noted, however, that the largest change between frequency and time spent was found between the categories of non-specific approvals and specific disapprovals. In other words, teachers in general appeared to make a large number of approving statements, but the comments tended to be non-specific in nature. On the other hand, not as many disapproving comments were made, but they represented a larger percentage of the time spent in verbal teacher reinforcement.

Results indicated an interesting relationship between the variables of teacher experience and student experience as they both relate to teacher reinforcement. Interactions seemied to suggest that more-experienced teachers of fered more verbal approvals to their less-experienced students. on the other hand, more-experienced teachers were more verbally 
disapproving with more-experienced students. In both instances, results indicated a higher degree of non-specific comments being presented. Teachers with less experience employed specific approvals significantiy more of ten than their more-experienced peers, while teachers with more experience exhibited more specific disapprovals with more-experienced students.

The interactions evidenced between teacher experience and student experience in relation to time spent in reinforcing comments raises some rather important issues. It is important to understand at this point that the mean for teacher experience in this particular study was 18.5 years. Less-experienced teachers, therefore, were defined in this particular case as those who had less than 18.5 years of teaching experience. Therefore, those teachers who were classified as "less-experienced" were not necessarily "inexperienced." The biggest questions raised in this instance would be centered upon trying to understand why more-experienced teachers are more verbally disapproving with their more-experienced students. "More-experienced" students in this study were defined as those with more than 3.5 years of piano instruction. Since many piano students are moving into intermediate levels by this stage, it may be that more demands were made of these students in order to achieve musical goals with the more-advanced literature they would have been encountering. It is also possible that students with more experience were perceived as "serious" students who enjoy music for its own sake, and therefore did not require as many approving comments. As Madsen and Duke (1985) reported, teachers untrained in behavioral techntques may have perceived approval to be insincere or ineffective with all students, and unnecessary for older students. If the teachers in this study perceived specific approvals in this manner, it would have explained why specific approvals were used less oiten. 
On a more positive note, the suggestion that less-experienced teachers were more specific with approvals may be indicative of successes being made with teacher training and dissemination of information regarding the importance of specific, positive feedback. It is also possible that more-experienced teachers made use of more sophisticated forms of reinforcement, including non-verbal expressions, activities, or physical proximity as reinforcement, instead of choosing to approve through verbal expression.

in the area of complete patterns of teaching, results indicated that all teachers in general made significantly less complete/correct patterns than they did complete/incorrect and incomplete patterns. A relatively high number of complete patterns exhibiting the three necessary components of teacher presentation, student response, and teacher reinforcement was observed. However, most of the complete patterns observed were defined as essentially incorrect due to the lack of specific information in teacher presentation and/or teacher reinforcement. It appeared that teachers in the private lesson could interact with students successfully with the use of teaching patterns. However, they tended to fall short in the area of specificity of presentations and reinforcements.

Conclusions drawn concerning the observations made in the various components of teacher presentation would only seem to be relevant in relation to what values the independent piano teacher held. For instance, teachers untrained in behavioral techniques may have felt that high percentages of disapproving comments were necessary or even desirable for effective teaching. Therein lies the rationale behind the post-hoc questionnaire, which was included in this particular study in order to compare teacher values with observed behaviors. Correlations between expressed teacher opinions and observed behaviors in the areas of social interaction, presentation of academic musical information, student 
performance, and teacher reinforcement revealed little, if any correlation between these variables in all cases. Coefficients ranged from -.31 in the area of specific reinforcement to 18 in the category of academic teacher talk.

However, many factors need to be explored in the analysis of results concerning the questionnaire. First, a fundamental weakness in the questionnaire was found in the fact that it required teachers to make generalizations concerning all students, and therefore, did not allow for student differences, which is understood by many to be a primary advantage of private instruction. Second, many teachers admitted either verbally or through written comments that they had simply never thought about components of teaching in terms of percentages. As a result, many of them admitted to assigning numbers somewhat arbitrarily to the questions presented. In fact, there was no reliability measure conducted on the questionnaire, and consequently, the responses given may not have proven reliable over time. A third consideration made with regard to the post-hoc questionnaire centered upon the fact that the way in which some of the questions were phrased may not have allowed for freedom of subject response. More specifically, the requests on the questionnaire to make certain responses total $100 \%$ may have limited subject response, inadvertently prohibiting them from considering or expressing opinions about other possible factors that they may have valued highly. Therefore, it is the conclusion of the investigator that the questionnalre may not have acted as a valid measure of the beliefs and values held by the subjects participating in this particular study.

In spite of the aforementioned weaknesses discussed in relation to the goal and purpose of the questionnaire, there appeared to be one issue associated with it that remains worthy of consideration. Although greater 
differences may have existed among expressed values held in relation to teacher presentation and student participation, teachers appeared to be very consistent in expressing percentages in relation to specific teacher reinforcement. All subjects recorded very high percentages when stating their beliefs concerning amounts of specific reinforcement which should be offered to students. The fact that this was also the highest negative correlation coefficient observed may be indicative of the fact that teachers consistently valued high amounts of specific reinforcement, yet were least likely to follow through in this area. These results support. those of Yarbrough, Price, and Bowers (1991), who demonstrated that values of teachers were not consistent with their behaviors until af ter self-evaluative feedback and training.

When reviewing the data collected overall, several factors should be taken into consideration. Although 47 lessons were analyzed for the present study, results were obtained from a relatively small number of teachers $(N=25)$. The limited geographical region from which subjects were drawn should also be considered as a factor when interpreting results. Although teachers reported wide differences in age, background, and teaching experience, all subjects were from the state of Louisiana, and a majority of thern were members of the same local teacher's organization. State certification requirements, as well as various opportunities presented to them through the local teacher's organization may have played a role in shaping the content and direction of individual lessons on a general basis.

A second factor to be considered in the current study centers around the collection of the data itself on audiotapes which were limited to 45minutes of time on each side of the tape. All teachers who participated in the study reportedly structured their lessons on a 30-minute or 45-minute schedule. However, nine of the 47 lessons analyzed for this study went 
beyond the 45-minute limit, resulting in an absence of recorded events for the last few minutes of those particular lessons. The specific time spent and frequency of events which occurred beyond the limits of the audiotape is not known. Since all subjects reported that the lessons were structured on a 45-minute basis, it is believed that the missing information was limited to a few minutes, at most. This certainly would have had some effect on results of total time and frequency in one or more of the components of teaching patterns which were being observed. However, it is believed that the additional data collected would not have altered results significantly in any category.

In light of the purpose of this study, the definition of the "typical" piano lesson should also be examined. One of the advantages of private instruction lies in the ability to tailor lessons to the needs of the individual student. Therefore, it would seem likely that wide variances in teacher-student interaction could be possible among lessons by the same teacher, in addition to wide variances among the practices of different teachers. In the present study, an attempt was made to achieve the "typical" lesson through the observation of two sessions of two different. students from each of 25 different subjects. Perception of student ability, in addition to being inciuded as a variable to be observed, was also included as a factor in the study in order to discourage subjects from audiotaping only their "ideal" students; therefore serving as a control to provide some type of "normality" among observations. However, it is possible that the "typical" lesson can only be fully understood through the observation of much larger numbers of students and teachers from a wider geographical region, each observed over longer periods of time. On the other hand, the consistency of the data collected in this study may indicate that the nature of private instruction is not a significant influence on verbal behaviors in general. 
Finally, it must be understood that the examination and quantification of verbal behavior is a tremendously difficult task. So much of what one intends to say is only fully understood when taking non-verbal behaviors into consideration as well. From the standpoint of uncierstanding any given message, it is clear that what a person understands is "filtered" through the biases and ideas that they themselves bring into a conversation. In other words, the effectiveness of any verbal communication or interactive teaching situation will be dependent not only on what the teacher says, but what the teacher does and more importantly, what the student perceives the teacher to be saying.

It must be reiterated that the scope of this study was rather limited. intending only to examine and describe a small part of the overall teachirig experience (i.e., verbal behavior), without making an attempt to label teachers as effective or ineffective. In light of this purpose, results from this study should not be generalized to suggest that the independent piano teacher is either effective or ineffective within any category on a general basis.

However, if the private music lesson and the independent music teacher are to continue to be important facets of music education, then several areas of possible improvement suggested by results of this study may need to be considered. First of all, results in the area of verbal teacher reinforcement should be examined. The independent piano teacher should consider, along with all music educators, the relatively low percentage of verbal teacher reinforcement offered in the music lesson. In addition, piano teachers should take note of the lower percentage of specific reinforcements, as well as the very low percentage of specific approvals observed in the private piano lesson. The use of disapproving verbal reinforcement in the private lesson setting should be re-exariiried 
in light of research which questions the effectiveness of such feedback techniques. In addition, teachers with more experience are encouraged to carefully reconsider the verbal reinforcement offered to all their students in generai, and to their more-experienced students in particular.

As far as specific teacher presentation and response is concerned, research results which point to the preference for higher amounts of teacher specificity should be considered. Independent piano teachers would appear to benefit greatly from simply being more specific in presentations and responses, for this would result in the positive change from an apparently large number of existing complete/incorrect patterns to a larger number of complete/correct patterns of teaching.

In light of the reactions and responses to the questionnaire presented in this study, piano teachers might consider specific goals and directions to be taken in the percentages of time spent within the private lesson setting, particularly with regard to the behavior of the teacher. It is important for the independent piano teacher to understand the importance of his/her own behavior as a factor in the teaching/learning process. In addition to an emphasis on content and methodology, piano teachers should also consider the importance of their behavior and how it functions in the private-lesson setting.

\section{Implications for Further Research}

In addition to possible areas of improvement suggested by this study, questions for further research are raised as well. Researchers should continue to explore the unique dynamics and operating factors present which shape the private music lesson. Comparisons and contrasts need to be explored and reported concerning operating variables found within the private-lesson setting as they relate to other settings of music education 
More specifically, a need for observation of teacher behavior within the college applied music environment, as well as group keyboard settings and lessons for the adult student would be important steps to take in the overall understanding of this very important facet of music education.

Results from the current study may indicate a need for the development of a new model of teaching, adapted for use in the rather unique setting of the individual music lesson. Taking into consideration the importance of gaining technical skills in piano instruction, the direction of future research may result in the formation of a new model for teaching which would possibly incorporate elements of the "training model" (Joyce \& Weil, 1986), in addition to the continued use of sequentral patterns. .

Student attitudes within the private-lesson setting are another area that should be examined more closely. Can piano students discriminate factors of effective teaching as identified by current research? Do piano students express preferences for certain variables of teacher behavior? Do rates of approval and disapproval significantly effect student attitude in the private lesson? What factors of teacher behavior need to be considered in light of long-term student participation and retention?

A more thorough exploration of the values held by the independent music teacher is suggested, especially at they relate to teacher behavior. Inquiries should continue to be made into the relationship of expressed beliefs to expressed behaviors. Researchers should also continue to explore methods of training teachers to be more specific and more approving within the setting of the private music lesson. Specific factors centered around the relationship of teacher experience to student experience and the apparent increase of verbal disapprovals used in these situations should be further explored.

Many questions remain yet unanswered and stand in need of further 
investigation. Empirical study of these factors is necessary and is encouraged in order to improve the nature of the music experience for all who participate. 
References

Arrau, C. O. (1990). Classroom behavior of exemplary group piano teachers in American colleges and universities. Dissertation Abstracts International, 51, 3661 A.

Ausubel, D. (1963). The psychology of meaningful verbal learning. New York: Grune \& Stratton.

Bastien, J. W. (1977). How to teach piano successfully (2nd ed.). Park

Ridge, IL: General Words and Music Co.

Becker, W. C. (1986). Applied psychology for teachers. Chicago: Science Research Associates, inc.

Benjamin, R. (1981). Making schools work. New York: Continuum

Berliner, D. C. (1976). Impediments to the study of teacher ef fectiveness.

Journal of Teacher Education, 27(1), 5-13.

Berliner, D.C. (1986). In pursuit of the expert pedagogue. Educational

Researcher, 15(7), 5-13

Eerliner, D. C.\& \& Tikunoff, W. J. (1976). The California beginning teacher

evaluation study: Overview of the ethnographic study. Journal of

Teacher Education, 27(1), 24-30.

Borich, G D. (1986) Paradigms of teacher effectiveness research.

Education and Urban Society, 18(2), 143-167.

Brophy, J. E. (1979). Teacher behavior and its effects. Journal of

Educational Psychology, 71, 733-750.

Brophy, J. E. \& Good, T. L. (1970). Teachers' communications of

differential expectations for children's classroom performance: Some

behavioral data. Journal of Educational Psychology, 61, 365-374. 
Brophy, J., \& Good, T. L. (1986). Teacher behavior and student achievement.

In M. Wittrock (Ed.), Handbook of research on teaching ( 3 rd ed.) (pp. 328-375). New York: Macmlllan.

Bruner, J., Goodnow, J., \& Austin, G. (1967). A study of thinking. New York: Science Editions, Inc.

Byo, J.L. (1990). Recognition of intensity contrasts in the gestures of beginning conductors. Journal of Research in Music Education, 38(3), $157-163$.

Camp, M.W. (1981). Developing piano performance: A teaching philosophy Chape! Hill, NC: Hinshaw Music, Inc.

Carnine, D.W. (1979). Direct instruction: A successful system for educationally high-risk children. Journal of Curriculum Studies, 11. $29-45$.

Carpenter, R. A. (1988). A descriptive analysis of relationships between verbal behaviors of teacher-conductors and ratings of selected junior and senior high school band rehearsals. Update The Applications of Research in Music Education, 2(1), 37-40

Chronister, R. (1977, Winter). Piano playing-- past, present, future. Keyboard Arts. 3-6.

Davis, O. L., \& Slobodiari, J. J. (1967). Teacher behavior toward boys and girls during first-grade reading instruction. American Educational Research Journal, 4 261-269.

DeGroat, A. \& Thompson, G. (1949). A study of the distribution of teacher approval and disapproval among sixth-grade pupils Journal of Experimental Education, 18, 57-75.

Dewey, J. (1916). Democracy and education. New York: Macmillan. Duke, R. A. (1986). Giving approval for appropriate behavior. Contributions to Music Education, 13, 23-30. 
Duke, R. A. (1987). Observation of applied music instruction: The perceptions of trained and untrained observers. In C. K. Madsen \& C. A. Prickett (Eds.), Applications of research in music behavior (Pp. 115124). Tuscaloosa, AL: University of Alabama Press.

Duke, R. A., \& Blackman, M. D. (1989, March). Proactive teaching: The effect of sequential task hierarchy on teaching behavior, student performance, and student attitude. Paper presented at the Research in Music Behavior Eighth National Symposium, Baton Rouge, LA.

Duke, R. A., \& Madsen, C. K. (1991). Proactive versus reactive teaching: Focusing observation on specific aspects of instruction. Bulletin of the Council for Research in Music Education. 108, 1-14.

Flanders, N. A. (1969). Analyzing teaching behavior. Reading, MA. Addison-Wesley.

Forsythe, J.L. (1975). The effect of teacher approval, disapproval, and errors on student attentiveness: Music versus classroom teachers. in C. K. Madsen, R. D. Greer, \&. C. H. Madsen Jr. (Eds.), Research in music behavior, (pp. 49-55). New York: Teachers College Press.

Friedman, P. (1976). Comparisons of teacher reinforcement schedules for studerits with different social class backgrounds. Journal of Educational Psychology, 68, 286-292.

Glasser, W. (1965). Reality therapy. New York: Harper \& Row, Publishers, Inc.

Good, T. L. (1979). Teacher effectiveness in the elementary school: What we know about it now. Journal of Teacher Education, 30(2), 52-64. Good, T. L. \& Brophy, J. E. (1972). Behavioral expression of teacher attitudes. Journal of Educational Psychology, 63, 617-627. 
Good, T. L. \& Brophy, J. E. (1974). Changing teacher and student Dehavior: An empirical investigation. Journal of Educational Psychologv, 66 , 390-405.

Gordon, W. J. J. (1961). Synectics. New York: Harper \& Row, Publishers, inc.

Grant, J. W., \& Drafall, L. E. (1991). Teacher effectiveness research: A review and comparison. Bulletin of the Council for Research in Music Education, $108,31-48$.

Haigh, N., \& Katterns, B. (1984). Teacher effectiveness: Problem or goal for teacher education. Journal of Teacher Education, 35(5), 23-27. Heller, M. \& White, M. (1975). Rates of teacher verbal approval and disapproval to higher and lower ability classes. Journal of Educational Psychology, 67, 796-800.

Housner, L. D. \& Griffey, D. C. (1985). Teacher cognition: Differences in plarining and interactive decision-making between experienced and inexperienced teachers. Research Quarterly for Exercise and Sport, 50, $45-53$.

Jackson, P. \& Lahaderne, $H$. (1967). Inequalities of teacher-pupil contacts Psychology in the Schools, 4 , 204-208.

Jellison, J. A. \& Wolfe, D. E. (1987). Verbal training effects on teaching units: An exploratory study of music teaching antecedents and consequents. In C. K. Madsen \&. C. A. Prickett (Eds.), Applications of research in music behavior (pp. 135-148). Tuscaioosa, AL: University of Alabama Press.

Joyce, B. \& Weil, M. (1986). Models of teaching (3rd ed.). Englewood Cliffs, N.d. Prentice-Hall.

Joyce, B., Brown, C., \& Peck, L. (1981). Elexibillty in teaching: An excursion into the nature of teaching and training New York. Longman. 
Kohlberg, L. (1976). The cognitive developmental approach to moral education. In D. Purpel \& K. Ryan (Eds.), Moral education: It comes with the territory (pp. 176-195). Berkeley, CA: McCutchan Publishing Corp. Kostka, M. J. (1984). An investigation of reinforcements, time use, and student attentiveness in piano lessons. Journal of Research in Music Education, $32(2), 113-122$.

Kowalchyk, G. (1989). A descriptive profile of piano pedagogy instructors at American colleges and universities. Dissertation Abstracts Internationa!, (50), 643 A.

Lancaster, O. E. (1974). Effective teaching and learning. New York: Gordon \& Breach.

Lorince, M. (1990). The training of performance teachers - then, now, and tomorrow. American Music Teacher, 39(5), 23-25.

Madsen, C. K. \& Alley, J. (1979). The effect of reinforcement on attentiveness: A comparison of behaviorally trained music therapists and other professionals with implications for competency-based academic preparation. Journal of Music Therapy, 16, 70-82. Madsen, C. K. \& Duke, R. A. (1985a). Perception of approval/disapproval in music education. Bulletin of the Council for Research in Music Education, 85, 119-130.

Madsen, C. K., Standley, J. M., \& Cassidy, J. W. (1989). Demonstration and recognition of high and low contrasts in teacher intensity. Journal of Research in Music Education, 37(2), 85-92.

Medley, D. M. (1979). The effectiveness of teachers. In P. L. Peterson \& H. J. Walberg (Eds.), Research on Teaching (pp. 11-27). Berkeley, CA: McCutchan Publishing Corporation.

Medley, D. M., Coker, H., \& Soar, R. S. (1984). Measurement-based teacher evaluation. An empirical approach. New York: Longman. 
Meyer, W. \& Thompson, G. (1956). Sex differences in the distribution of teacher approval and disapproval among sixth-grade children. Journal of Educational Psychology, 47, 385-396.

Mitchell, M. M. (1990). Theoretical orientations of Chapter I reading teachers: Consistency between beliefs and practices. Dissertation Abstracts International, (51), 4009A.

Moore, R. S. (1976, November). Videotaped comparisons of beginning versus experienced music specialists in the use of teaching time: Developing and piloting the Music Teaching Interactions-Activities Form. Paper presented at the Second National Symposium on Research in Music Behavior, Milwaukee, W!

Moore, R. S. (198i). Comparative use of teaching time by American and British elementary music specialists. Bulletin of the Council for Research in Music Education, 66-67, 62-68.

Murray, K. C. (1975). The effect of teacher approval/disapproval on musical performance, attentiveness, and attitude of high school choruses. In C. K. Madsen, R. D. Greer, \& C. H. Madsen, Jr. (Eds.), Research in music behavior (pp. 165-180). New York: Teachers College Press. Penick, A. (1988). Growing awareness: Notes from the piano studio. In J. T. Gates (Ed.), Music education in the United States: Contemporary issues (pp. 287-296). Tuscaloosa, AL: The University of Alabama Press.

Peterson, P. L. (1979). Direct instruction reconsidered. In P. L. Peterson \& H. J. Walberg (Eds.), Research on teaching (pp. 57-69). Berkeley, CA: McCutchan Publishing.

Piaget, J. (1952). The origins of intelligence in children. New York:

International Universities Press. 
Power, K. M. (1990). Teachers and parents as partners: The key to a successful parent-teacher relationship. American Music Teacher, 39(4), 22-23.

Price, H.E. (1983). The effect of conductor academic task presentation, conductor reinforcement, and ensemble practice on performers' musical achievement, attentiveness, and attitude. Journal of Research in Music Education, 31, 245-257.

Price, H. E. (1985). Teaching in rehearsal: It's as easy as 1-2-3. Update: The Applications of Research in Music Education, 4(1), 11-13.

Price, H. E. (1989a, March). Assessment of sequential patterns of instruction in music: A preliminary investigation. Paper presented at the National Conference on Music and Technology, Nashville, Tennessee. Price, H. E. (1989). An effective way to teach and rehearse: Research supports using sequential patterns. Update: Applications of Research in Music Education, $8(1), 42-46$.

Price, H. E. \& Yarbrough, C. (1990, July). Validation of sequential patterns of instruction in music. Paper presented at the Thirteenth International Research Seminar in Stockholm, Sweden.

Rist, R. (1970). Student social class and teacher expectations: The selffulfilling prophecy in ghetto education. Harvard Educational Review, $40,411-451$.

Robert, W. (1981). Four-way piano teaching: Criticism, demonstration, analysis, inspiration. In D. Agay (Ed.), Teaching piano (pp. 603-608). New York. Yorktown Music Press, Inc.

Robinson, H., \& Jarvis, R. L. (1967). Teaching piano in classroom and studio. Washington D. C.: Music Educator's National Conference. Rogers, C. (1979). Freedom to learn. Columbus, OH. Charles E. Mlerrill Publishing Company. 
Rosenshine, B. (1976). Recent research on teaching behaviors and student achievement. Journal of Teacher Education, 27, 61-64.

Rosenshine, B. (1979). Content, time, and direct instruction. In P. L.

Peterson \& H. J. Walberg (Eds.), Research on teaching (pp. 28-56).

Berkeley, CA: Mccutchan Publishing.

Rosenshine, B., \& Furst, N. (1973). The use of direct observation to study

teaching. In R. M. W. Travers (Ed.), Second handbook of research on

teaching (pp. 122-183). Chicago: Rand McNally.

Rosenshine, B. \& Martin, M. (1974). Teacher education and teacher

behavior. Educational Researcher, 3(7), 11-12.

Rosenshine, B., \& Stevens, R. (1986). Teaching functions. In C. M. Wittrock

(Ed.), Handbook of research on teaching (pp. 376-391). New York:

Macmillan.

Sadker, M., and Sadker, D. (1985). Sexism in the school room of the '80's Psychology Todav, 19(3), 54-57.

Schmidt, C. P. (1989). Applied music teaching behavior as a function of selected personality variables. Journal of Research in Music Education, 37(4), 258-271.

Silberman, M. (1969). Behavioral expression of teachers attitudes toward elementary school students. Journal of Educational Psychologv, 60 , $402-407$

Sigel, 1. (1969). The Piagetian system and the world of education. In D. Eikind \& J. Flavell (Eds.), Studies in cognitive development (pp. 465489). New York: Oxford University Press.

Single, N. A. (1990). A summary of research-based principles of effective teaching. Update: Applications of Research in Music Education, $\underline{Q}(2)$, $3-10$. 
Skaggs, H. G. (1981). The teacher-student relationship: Some commonsense suggestions. In D. Agay (Ed.), Teaching Piano (pp. 631-632). New York: Yorktown Music Press, inc.

Sparks, G.M. (1988). Teacher's attitudes toward change and subsequent improvements in classroom teaching. Journal of Educational

Psychology, $80(1), 111-117$.

Wagner, M. J. \& Strul, E. P. (1979). Comparisons of beginning versus experienced elementary music educators in the use of teaching time Journal of Research in Music Education, 27, 113-125.

Wolfe, 0. E. (1989, March). The effect of a visual prompt on changes in antecedents and consequents of teaching behavior. Paper presented at the Research in Music Behavior Eighth National Symposium, Baton Rouge, LA.

Wolfe, D E. \& Jellison, J. A. (1990). Music and elementary education students' evaluations of music-teaching scripts. Journal of Research in Music Education, 38(4), 311-321.

Yarbrough, C. (1975). The effect of magnitude of conductor behavior on performance, attentiveness, and attitude of students in selected mixed choruses. Journal of Research in Music Education, 23, 134-146

Yarbrough, C. \& Price, H. E. (1981). Prediction of performer attentiveness based on rehearsal activity and teacher behavior. Journal of Research in Music Education, 29(3), 209-217.

Yarbrough, C. \& Price, H. E. (1989). Sequential petterns of instruction in music. Journal of Research in Music Education, 37(3), 179-187.

Yarbrough, C., Price, H. E., \& Bowers, J. K. (1990). The effect of knowledge of research on rehearsal skills and teaching values of experienced teachers. Update: Apolications of Research in Music Education, 2(2), $17-20$. 
Young, B. G. (1990). The use of computer and keyboard technology in selected independent piano studios. Dissertation Abstracts international, (51), 1948A. 
APPENDIX A.

TEACHER/STUDENT INFORMATION SHEET 
TAPE NUMBER:

\section{TEACHER INFORMATION}

AGE:

YEARS OR MONTHS OF TEACHING EXPERIENCE.

NUMBER OF STUDENTS YOU ARE CURRENTLY TEACHING:

ARE YOU STATE/NATIONALLY CERTIFIED? YES NO

HIGHEST LEVEL OF EDUCATION. (INCLUDE CURRENT STUDY IF APPLICABLE):

IF COLLEGE, GIVE NAME OF DEGREE:

IF COLLEGE, GIVE MAVIOR: PERFORMANCE PEDAGOGY
MUSICEDUCATION

STUDENT INFORMATION

$\begin{array}{ll}\text { STUDENT \# (SIDE A) } & \text { STUDENT \#2 (SIDE B) } \\ \text { AGE: } & \text { AGE: } \\ \text { HOW LONG HAVE YOU } & \text { HOW LONG HAVE YOU } \\ \text { TAUGHT THIS STUDENT? } & \text { TAUGHT THIS STUDENT? } \\ & \\ \text { TOTAL YRS/MOS. OF } & \text { TOTAL YRS/MOS OF } \\ \text { LESSONS: } & \text { LESSONS } \\ \text { I CONSIDER THIS STUDENT TOBE: } & \text { I CONSIDER THIS STUDENT TOBE. } \\ \text { (CIRCLE ONE) } & \text { (CIRCLE ONE) } \\ \text { AVERAGE } & \text { BVERAGE }\end{array}$


APPENDIX B

TEACHER QUESTIONNAIRE 


\section{QUESTIONNAIRE}

Please take a few moments to give your opinion to the following questions. Be sure that your numbers from each of the first three questions add up to $100 \%$

1. In your opinion, approximately what percentage of a private piano lesson should be spent in the following areas?

Social Conversation

Presentation of musical information by the teacher

Student activity (playing, talking, etc.)

Feedback for student activity

Total

2. Of all musical information presented by the teacher, what percentage of the time should be spent in the following areas?

Teacher talking

coaching (teacher instructing

while student plays)

Modeling (playing or singing)

by the teacher

Total

$100 \%$

3. Of all feedback given for student activity, how should percentages be divided between the following areas?

Approving comments

Disapproving comments

Total

$100 \%$

4. In your opinion, what percentage of feedback for student activity needs to be specific? (For example, Specific: You shaped that phrase nicely! Non-specific: Good!) 


\section{ADPENDIX C \\ TRANSCRIPT OF SAMPLE LESSON: \\ YOUNGER STUDENT; LESS-EXPERIENCED TEACHER}


TEACHER EXPERIENCE: 6 YRS.

STUDENT AGE: 9

STUDENT EXPERIENCE: 6 MOS.

PERCEIYED ABILITY: AVERAGE

TOTAL LESSON TIME: $42: 45.38$

ACADEMIC MUSICAL INFORMATION: $44.54 \%$

MODELING: $12.30 \%$

COACHING: $14.98 \%$

TEACHER TALK. $72.72 \%$

DIRECTION: $4.24 \%$

STUDENT FARTICIPATION. $33.44 \%$

PERFORMANCE/VERBAL RATIO: $96 / 4$

TEACHER REINFORCEMENT: $5.99 \%$

APPROVAL/DISAFPROVAL RATIO: $55 / 45$

SPECIFIC/NON-SPECIFIC RATIO: $44 / 66$

SEQUENTIAL PATTERNS

COMPLETE/CORRECT: $10.88 \%$

COMPLETE/INCORRECT: $43.52 \%$

INCOMPLETE: $45.60 \%$

T Um.... Let's start with technique. All right. Number 3.

$S$ (plays)

T OK. All the way through the end now, keep your steady beat. . your steady tempo. All right? Start right here

$S$ (Diays)

$T$ (while student plays) Down, up, down, up...1, 2, 3, up.

(student stops) OK now. You have to be as careful about releasing your notes as you are about putting them down. All right? (plays) 1,2,3, up. And make sure both hands come up together. Try that. Just the stepping down.

$S$ (plays)

$T$ Now start on $G$ and come down.

$S$ (plays)

T $1,2,3$, up. That's much better. You see? That gives you a nice, clean release instead of um, well, I think I'll get it. . OK? All right. Did you have to do number 4? No. Let's do number 4 next time. Now. Number 4 is gonna start out with half notes. Then you go to quar ter notes, and then to eighth notes. You're not going to um. . the tempo's not supposed to 
get faster. Your nate values are gonna get shorter, so it's gonna seem like it gets faster. All right? Let's try it. It goes up the $C$ scale, and then down the $C$ scale. That's all it is. Ready, and. .

$S$ (plays a chord)

T Oops! Hand position. Ready, go.

$S$ (plays)

$T$ (while student plays) 1, 2. Oops!

(student stops) Let's go a little slower than that. 1, 2, ready, play.

$S$ (plays)

$T$ (while student plays) $1,2,3,4,1,2,3,4,1,2,3,4,1,2,3,4,1,2,3,4,1,2,3,4$, 1 - and-2-and-3-and-4-and-OK.

(student stops) I'm sorry. I haveri't shown you what eighth notes are. Eighth notes are iwo sounds to a beat. Quar ter notes are one sound to a beat, eighth notes are two. So instead of (claps) 1, 2, 3, 4, it's 1-and-2-and-3-and-4-and. (plays) (while playing) 1-and-2and-3-and-4-and-1. (stops) Do that for me.

$S$ (plays)

T OK, keep a beat!

$S$ (plays)

$T$ OK, Kristin. Watch my hand. First of all, keep your wr ist up a littie bit. Don't let it fall down, OK? Keep your fingers close to the keys.

$s$ (plays)

$T$ Again.

$\varepsilon$ (plays)

T All right

$S$ (plays)

T OK. Start with the. . start with thie quarter notes, and then go to the eighth notes. 1,2, ready, and. .

$S$ (plays)

T Uh uh. Too fast. 1, 2, ready, go

$S$ (plays)

$T$ (while student plays) $1,2,3,4,1,2,3,4,1$-and-2-and-3-and-4-and-1.

(student stops) See? You have to play these a little slower, I think, still. Ready, let's slow it down a little more. 1, 2, ready, play.

$S$ (plays a few notes)

$T$ No, you're not going as slow as I am. Count with me. Ready, play

$S$ (plays)

$T$ (while student plays) $1,2,3,4,1$-and-2-and-3-and-4-and-1-and-2-and-3-and-4and-1. 
(student stops) That's the idea. Do you see? 1, 2, 3, 4-and1. OK, Kristin. Um, what scale are you doing in Keyboard? $F$ ? And you've done $G$ already, right? I want you to transpose this to $F$ and to $G$. Let's try $G$ first. Put your hands in $G$ position. Right here. OK. Now, you're gonna play the same pattern. It goes up the scale by steps, right? And then down the scale. Ready, go.

$S$ (plays a few notes)

$T$ Yeh, but you gotta go real slow.

$S$ (plays)

$T$ (while student plays) 1-and-2-and-3-and-4-and. Listen, Kristin.

(student stops) The eighth notes go 1 -and-2-and-3-and-4-and-1-and-2-and-3-and-4and. See how slow it has to go? Ready, play

$S$ (plays)

$T$ (while studerit plays) 1-and-2-and-3-and-4-and-1-and-2-and-3-and-4-and- 1 -and2-and-3-and-4-and-1-and-2-and-3-and-4-and-1, 2-and-3-and-4-and-1-and-2and-3-and-4-and-1-and-2-and-3-and-4-and-1.

(student stops) Really good! Real good. Play your $F$ scale for me. OK, where are you gonns start?

$S F$

$T$ OK. First of all, find $F$. There's $F$

$S$ on

T OK. Now, $F$ has a flat. Do you remember which note is flat? Maybe we could put flats in.

$S$ The $F$ and the $G$ ?

$T F, G, A, B-f l a t, C$. OK? Play it for me

$S$ (plays)

$T$ OK, how do you play B-flat?

$S$ (plays a note)

$T$ All right. Try it again.

$S$ (plays)

$T$ Go back down.

$S$ (plays)

$T$ All right. Right hand.

$S$ (plays)

$T$ Put hands together.

$S$ (plays)

$T$ Now. Play your tonic chord.

$S$ (plays)

$T$ Left hand.

$S$ (plays)

$T$ OK. All three of them. Try to get them all three down. 
$S$ (plays)

$T$ There you go.

$S$ (plays)

$T$ The right hand's real good. Try that left hand again.

$S$ (plays)

$T$ There you go! That's the idea. You just have to get used to how it feels. If you stiffen this finger just a little bit, (plays) that'll help.

$S$ (plays)

$T$ Oops. Again.

$S$ (plays)

$T$ One more time.

$S$ (plays)

$T$ Work on that. Um, let me write that down Transoose.... transpose means to play it in another position or another key. ... to $F$ and $G$. Play one time soft, piano. . . and one tirie forte. What does forte mean? Fiano is soft, and forte means..

$S$ Loud

$T$ Loud. OK. Exercise number 4 for next week. OK, get your $F$ iano book out. I want you to practice your $F$ scale again. OK? Go ahead.

$S$ (plays)

T OK, wait. Since you stopped, do you want to start over again? Look at your dynamics. What does it say?

$54 / 4$

$T$ That's your time signature. Dynamics tells you whether to play soft or loud. What does it say?

$S$ Soft.

$T$ Soft. P stands for soft, right. What ward?

$S$ Fiano

T Piano. Yery good. OK. Try it.

$S$ (plays)

T OK, Kristin. Is that giving you a hard time?

$S$ Yes

T Um. . Let's look at it a second. It goes up, and then comes down. You've got. . not having too much trouble with the first part. You're getting it most of the time. But this one is getting you, huh? Look, it's two notes. E, F, E. On this one, go up and come back.

$S$ (plays)

$T$ Fractice that.

$S$ (plays)

$T$ Starts on $E$. 
T\&S (both play)

$T$ (while playing) $E, F, E$ :

(student stops) Say it. No. Just this.

(plays) (while playing) $E, F, E$.

$S$ (plays)

$T$ Kristin. E. Where's E?

$S$ (plays a note)

$T$ OK, now. Where's F?

$S$ (plays)

$T$ Do it again. Same eighth notes.

$S$ (plays)

$T$ Now louder. Not your hand. Your wrist.

$S$ (plays)

$T$ Again

$S$ (plays)

$T$ Again

$S$ (plays)

$T$ Now, do this (plays) (while playing) $D, E, F, E$.

$S$ (plays)

$T$ onc emore

$S$ (plays)

T OK. Start here at the beginning again. 1, 2, ready, go.

$S$ (plays)

T Good, Kristin! Do it again. Do it three times.

$s$ (plays)

T OK, you gotta let go back up.

$S$ (plays)

$T$ (while student plays) $D, E, F, D, E, F, E$. (studerit plays) Good! That's one time. Now do it again.

$S$ (plays)

$T$ That's two times.

$S$ (plays)

$T$ Three times. OK, stop. Now, what we just did is practiced it. Now when you have trouble with something at home, you pick the part that gives you the most trouble, and you play that part by itself first, OK? Instead of going back to the beginning and star ting over every time. You can learn it a lot faster and a lot better if you just take the little parts that gives you the most trauble on it. Figure that out first. Play it about five times in a row, then go back and add o little more to it. Then go back and try to play the whole phrase. OK? See? Now right here, you're starting on $a$ instead of an $E$. This starts on $E$. You need to watch this note 
right here. OK? Play this. . play this little... phrase.

$s$ (plays)

$T$ Again.

$S$ (plays)

$T$ Oops. What about rhythm?

$S$ (plays)

T OK, good. All right. Work on this one a little bit more, Kristin. OK, have you had that more than. . Hove you just had it one week? Poge 34? Yeh. Well, work on it one more week. Let me hear Noah's Ark. You didn't learn Noah's Ark, did you?? Not yet. We just talked about what a tie is, right?

$S$ Um hmim.

T OK. Well, let's look at Noah's Ark. What's the time signature?

S $3 / 4$ ?

T OK. So that's how mariy beats in a measure?

S 3 ?

T 3. And clap. . clap beats in sets of three for me. Where does your accent fall? Where is the strong beat. . when you have three? Clap. . clap the first line. Ready, clap?

$S$ (clans)

T That's it. What about the last note. How many counts does it get?

$S$ Thiree?

$T$ Three. What. what's it called?

$S$ Half dotted?

T Dotted half note. That's right. OK. Try to play the first line. Look for your steps and your skips.

$S$ (olays)

T OK, wait. Hold it one more.

$S$ (plays)

$T$ Good, Kristin. Once more.

$S$ (plays)

T Wait a minute. It doesn't start that way. Look.

$S$ (plays)

T You've gotta remember to go all the way up to $G$. OK? When you're practicing, be careful about that. Try the left hand.

$S$ (plays a few notes)

$T$ Oops.

$S$ (plajs)

T Look at this. Does this look familiar? It steps up and it steps back down. Where do. . where do you have that over here? Same pattern? It's not the same notes, but it's the same 
pattern.

5 Right there.

$T$ That's right. OK? Step up, and step back down to the same note.

$S$ (ploys)

$T$ Good. One more time, the last line. Ready, and, play...

$S$ (plays a few notes)

$T$ Dops. The wrong way.

$S$ (plays)

$T$ OK.

$S$ (plays a few notes)

$T$ All right. OK, did you play the $C$ twice?

$S$ Yeh.

(plays)

$T$ (while student plays) $1,2,3$, hold.

(student stops) You don't play it twice. Hold it. 1, 2, 3, hold, 2, 3. Let's look over and talk about tie again. We just mentioned it last time. And I think you have some ties in your recital piece, right? In your Waltz? Are there ties in here?

$S$ Um hmm

$T$ What do you do when you have a tie? There are no ties in here. Yes, there are. There's one. What do you do when you have tied notes? (pause) C'mon, Kristin. You play the first ane. and the second one is. .

$s$ You hold?

$T$ You hold it. So, on Noah's Ark, on the last note, you go (plays) (while playing) $1,2,3$, hoid 2, 3. You do it.

$S$ (plays)

$T$ (while student plays) 1,2,3, hold, 2,3.

(student stops) Play that last line. 1 , ready, go. .

$S$ (plays)

T (while student plays) $1,2,3$, hold, 2,3 .

(student stops) That's it. OK. Um, I want you to learn Noah's Ark. Turn. Let me hear your Waltz before I decide what else we'll do this week. You can leave your Piano Book right. . . just leave it open.

$S$ (plays)

$T$ OK, Kristin. Pretty good. Real good notes. Right here, you had one hittle thing. You kind of got this a little bit wrong. Play these two. It's $F$-sharp and $G$. OK. Let me show you something. Don't twist your hands. When you have to play a sharp, I know it feels kind of funny. But you don't want to twist your hand around this way to do it. You want to keep your hand (plays a chord) like that You're gonna use your fifth finger on $G$ (plays a note), and the 4 th finger on the F-sharp (plays a note) 
$S$ (plays a chord)

$T \quad O K$, do it back. . This $G$, and $F$-sharp.

$S$ (plays a chord)

$T$ Now play it. Twice.

$S$ (plays)

$T$ OK, can you play it ( $p$ lays)

$S$ (plays)

$T$ (plays)

$S$ (plays)

$T$ And then it goes down to. . the 5 th finger stays on $G$, and this goes to $F$ natural. (plays)

$s$ (plays)

$T$ Do it again

$S$ (plays)

T Try to get them both down together. 1, ready, go. .

$s$ (plays)

$T$ OK, Kristin. Now. This is a Waltz. The downbeat. . your first beat is ganna be your strong beat. And your chords are gonna be soft. Listen. You want it to sound kind of like this. (plays) (while playing) $1,2,3,1,2,3,1,2,3$. (stops) Like that. (plays). All right, now. Here's your phrase mark. Do you see the slur? These two are connected. They're played legato, and legato means what?

$S$ Smooth

T Smooth. (plays) And connected (plays) You can think of it like this (plays) (while playing) Down, up, up, down, up, up, down up, up. (stops) OK, you try that.

$S$ (plays a note)

$T$ Oops.

$S$ (plays a few riotes)

T Not too loud. It says mezzo-piano. That means maderately soft.

$S$ (plays)

T OK. Let it have some bounce. It says happily. Make it sound happy. You're waltzing around the room. Bum, bum, bum, bum, bum, bum,

$S$ (plays)

$T$ That's better! Do it again.

$S$ (plays)

T (while student plays) $1,2,3,1,2,3,1,2,3$.

(student stops) All right. Now. Um, go ahead and play the first two lines. First two lines Un hmm

$S$ (plays)

$T$ OK, now. Right there, Kristin, you want that to (plays). You play it. 
$S$ (plays)

T You dor't want a break in between. (sings) 1, 2, 3, 1, 2, 3 .

$S$ (plays)

$T$ No, it doesn't go to that note.

$S$ (plays)

$T$ Keep your beat even.

$S$ (plays)

$T$ (while student plays) 1, 2, 3, 1. 1, 2, 3, 1,2, 3 . (student stops) That's the idea. Start in the beginning again.

$S$ (plays)

T Lighten up. (sings) Boom, boom, boom. (stops) Not heavy.

$S$ (plays)

$T$ Now go on. It's gonna be just like the first line. The third line and the first line are exactly the same. Go ahead.

$S$ (plays)

$T$ Oops. You gotta hold it.

$S$ (plays)

$T$ (sings) Ba, da, da.

$S$ (plays a few notes)

T Oops. What note does it start on?

5 (plays a few notes)

T OK. And right here, you have what?

$S$ Dotted half?

$T$ Hur?

5 Dotted half

T Datted half note. And what's... what's it name? Which. . which note? $A, B, C$. $S$ B.

$T B$ ?

$S E, G$

$T$ OK. Do it for me.

$S$ (plays)

$T$ Play that. I started right here.

$S$ (plays)

$T$ OK. (sings) $D, E, F, E, D, C$. (stops)

$S$ (plays a few notes)

$T$ un uh.

$S$ (plays)

$T$ (plays along) (while playing) $D, E, F, E$. 
(both stop) Look. It's gonna go up, and it's gonna turn around and go back down. OK? 1, ready go...

$S$ (plays)

$T$ (while student plays) D, E, F, E, D, C. Hold.

(student stops) Good, Kristin. Do you see how it works? All right, now your left hand is now gonna ploy what your right hand played here. With the $G$ and the $F$-sharp, the $G$ and the F-natural. Try those two. (plays)

$S$ (plays)

$T$ (plays)

$S$ (plays)

$T$ (plays)

$S$ (plays)

$T$ That's it. Try it again.

$S$ (plays)

$T$ Now you have a third. Still the same $G$ in the top, so what's this? (plays)

$S$ (plays)

$T$ watch right there

$S$ (plays)

T No. You dor't have oll three notes. Just. . Just what?

$S$ G. And $F$ ?

$T G$ and...

$S E$

T $E$

$S$ (plays)

$T$ The last note is? (pause) C. Good.

$S$ (plays a note)

T OK, now. The last line goes like this, Kristin. (plays) Listen again. (plays). You do it. Take your time. $1,2,3,1$, ready, play.... Starting on that $B$

$S$ Here?

T Um hmm. 1... Right here. Are you ready? 1, ready, play. .

$S$ (plays)

T OK. Your first riote has a rest with the left hand. So it's (sings) bum, chunk, chunk, boom, chunk, chunk, boom, chunk, chunk.

$S$ (plays)

$T$ Chunk. Don't leave off a beat.

$S$ (plays a note)

$T$ OK. Now. I want you to work on that. Learn the. . learn the nates for the rest of the first page. OK? And basically, that's just learn the last line, right? Cause you've already learned the first two. And rememter, one and three are alike. OK, Kristin. I want you to 
start it one more time. And I want you to. . I want you to really try to get the feel of a waltz. It's boom, chink, chink, boom, chink, chink, 1, 2. Did you ever dance a waltz? It's like this. C'mon. Come stand up. All right. You're gonna step. You're gonna take one big step, and two small steps. $1,2,3,1,2,3$. Don't worry about any pattern or anything like that. Let's just walk in a line. OK, a big step and two small steps. 1, ready go. $1,2,3,1,2,3$. You've gotta talk it with me. C'mon. You can talk. 1, ready, go.

T\&S $1,2,3,1,2,3$.

T Look, I'm stepping on 2, 3. I'm taking tiny steps, like this. Move your feet. OK. 1, ready, go $1,2,3,1,2,3,1,2,3,1$, turn around. $1,2,3,1,2,3,1,2,3$. Can you feel that? Huh?

$S$ Uh uh

T Try it again. Let's not take such big steps. 1, ready, go. $1,2,3,1,2,3,1,2,3,1$. See? And you have to have the same feel in your song. $1,2,3,1,2,3$. OK? You do it. Try to play it.

$s$ The whole song?

$T$ Yeh. Just play. . Yeh, play through the whole song. 1, ready, go...

$S$ (plays a few notes)

$T$ Softer. Lighter. OK?

$S$ (plays)

$T$ (while student play's) $1,2,3 \ldots 1,2,3 \ldots$ Up down....

(student stops) OK. Now you're. . it switches. Your right hand's gonna take the melody. I'll let you work on that. Play the second page for me.

$S$ (play's)

T OK. Whos, whoa, whos! We've gotto have a steady beat, all right? We can't have four different meosures and four different tempos. 1, ready, go...

$S$ (plays)

$T$ (while student plays) $1,2,3,1,2,3,1,2,3$

(student stops) Why did i pick up your thumb? Why did I do that? Hmim? How many counts does this $G$ get? How many counts is that?

S 2?

$T$ Huh? How many? I didn't hear you.

$S$ 1?

T 1? That's right. So after it gets its one count, you can't hold it down until you get to here. OK? It's got to rest.

$S$ (plays)

$T$ (while student plays) We talked about that and you're just holding down forever, through this rest right there!

(student stops) You've got to let it up! 
$S$ (plays a few notes)

$T$ Yeh. OK?

$S$ (plays)

T Uhh! That's a half note! Where's the half note? (pause) Yes ma'am. Do it again.

$S$ (Plays)

$T$ (while student plays) $1,2,3,1,2,3,1,2,3$, half note. $1.1,2,3 \ldots 3 . \ldots$ (student stops) OK. Now. Kristin. Play your last line. Put your pedal down, and make it real clear. Make the notes real clear.

$S$ (plays)

$T$ There you go. Use your second finger to play that $C$ when you cross over. Use finger number 2. Start.

$S$ (plays)

T OK. Now try to get there a little sooner, so that they don't have to wait. (sings) bum, bum, bum, bum, bumi, bum.

$S$ (plays)

$T$ Keep your pedal down. Now, wher you pick your pedal up, you gotta lift it up quick. Just like we talked about the release when you were doing your technique. You gotta release your pedal just like you release your notes. You wanna let it up all at once, not just a little at a time. OK? Play it one more time.

$S$ (plays)

$T$ Nope. You're letting it up way too soon. OK. Listen. Move over. Pedal down (plays) (while playing) $1,2,3,1,2,3$, up. (stops) OK?

$S$ (plays)

$T$ (while student plays) $1,2,3$, up. (student stops) All right. That was a little better. You see? You've gotta make sure that you're hoiding all the way down, cause as soon as you start releasing a little bit, those dampers are gonna start to fail back on the strings, and you'll stop the sound. Do you know what happens when you press the pedal? Huh?

$S$ It's different?

$T$ Get uo here and look. Do you see these? These are called dampers, and do you see how they rest on the strings?

$S$ Um hmm

$T$ The strings make the sound. When you hit a key. . . (plays a note). . Do you see underneath there? The little white thing?

S Um hmm

$T$ That's a hammer. When you hit a key, the hammer hits the string. The damper comes up When you (plays a note). . See, I pushed a key. Now, when I let my finger up, the damper falls back down, right? Yeh. Fress the pedal. Well, you can't press it, so let me. . you get over here. So we can see it. . I'il press. OK, now. When I put the pedal down, watch what 
happens to all the dampers.

$S$ They come up.

T Um hmm. Now. If I hit a key, (plays) it's gonna ring for as long as the sound will ring, because there's nothing to stop the sound. You see? As soon as I let the pedal up. . watch the damper. And the sound stops instantly. As soon as that piece of felt hits that string, it stops. What does it stop doing. . What causes the sound in the first playce? Do you know? You haven't learned it in science?

$S$ Um, we're on sound.

$T$ You're on sound? I want you to figure out why. . why the string makes the sound, when something hits it, OK? The damper hits the string, and the string does something that causes the sound. Can you figure out what it might be? Hmm? Did you ever take a rubber band and pop it?

$S$ That's what we did today.

$T$ Did it make a sound? Did it vibrate? OK, that's what cause the sound. The vibration in the string, OK? All right. OK, have a seat. Now, you know why your pedal works, and what it's doing, OK? Um, go back and do the second line, where you have those dotted half notes played together, hands together. Yes. Play that. Play that second line. And Kristin, what I want. you to think about is cornecting those dotted half notes. Make it smooth. Like so (plays). OK, this is the [?]. OK. Don't make everything all the same, because then it sound like da, dà, dà, dâ. You want to make it sound musical, and to make it sound musical, you have to have louds and softs. All right? Try it again.

$S$ (plays a few notes)

$T$ OK, now. Flay this one just a little stronger than this one. (sings) ba, da. (stops) Like that.

$S$ (plays a few notes)

$T$ OK, they sounded the same to me. Can you make the second one quieter? (plays)

$S$ (piays)

$T$ Yes.

$S$ (ploys)

T Again

$s$ (plays)

$T$ Yes, Kristin! That's much prettier if you do it that way. OK, instead of ( $p$ lays). That doesn't sound too good, does it? No. All right. Now. Play it again, that second page. And I wanna hear your half notes. I warit you to count those half notes. On that $E$, you missed it both times. Where is that? We stopped and talked about it.

$S$ Right hiere?

T Um hmm. And you got it right when we stopped, and then you got to the third line and you did it again. OK? Play the last page. 
$S$ Here?

$T$ Yes. No, the whole page. The whole last page.

$S$ (plays)

$T$ Oops. Do it again. What do you need to do?

$s$ (plays)

$T$ Nice

$S$ (plays)

$T$ Oops. This is quiet.

$S$ (piays)

$T$ Keep it moving. Don't stop at the end of that line.

$S$ (plays)

$T$ Good, Kristin. Much better release on your pedal, your. . your little um, dotted half notes up there hands together was beautiful! That was just right. I still want you to work on. . on all your quarter notes, and getting those bum. I want that same kind of sound. Boom, chink, chink, bum. Then on the second page, it needs to just kind of flow. All right, we'll work on that some more next week. You're doing really well. I would like you to memorize. . Have you menior ized any of it, yet? Can you play me...

$S$ Just that part.

T You have memorized that page? Let's memor ize the first page for next week, so we wori't be too far behind, OK? We've only got three weeks left. All right? So let's try to get the first page memorized. Um, I think for your second song, I haven't assigned you anything yet. I don't think sn. No. We're gonna choose something out of one of these books. You' re on. which one of these are you on?

$s$ Um. [?]

$T$ Fat Cats? Old Womarr is a nice one. OK, instead of me hear ing these two today, let's go and look at old Woman. Because this... this is something you might could play. It's not too hiard, and it's a nice little song. Hands toge... start notw with skips on your tonic chiord. What's the key? The hand position? What hand position?

$S G$

$T$ The left hand starts, but what hand position, $C$ or $G$ ?

$S G$

$T$ OK, I'm confusing you. It starts on $a$. The first note is a $G$. But the hand position is $C$. OK? Now the first note is a $G$ in your left hand and your right hand. Bass clef first, $O K$ ? Then you use treble clef.

$S$ (plays a few notes)

$T$ Now we just said, what's your first note?

$S 0$

$T$ OK, riow.

$S$ (plays) 
$T$ All right, now. Kristin. The time signature is what?

$S 4$

T 4/4. And the first note is. ... a half note. So it's got to be (claps) (while clapping) 1,2 , $3,4,1,2,3,4$

$S$ (plays)

$T$ All right now. Stop. Let's do that again. (plays) (while playing) $1,2,3,4,1,2,3,4$. (stops) Go.

$S$ (Plays)

T All right now. The quar ter notes move a little bit better. I'm gonna make you do it one more time, and then we'll go on. Ready, and....

$s$ (plays)

$T$ (while student plays) $1,2,3,4,1,2,3,4,1,2,3,4$. Wait, wait (student stops) This is repeating

$S$ (ploys)

$T$ Now how many times is it repeated?

$S 2$

T 2,3 !

$S$ on.

(plays)

T (while studert plays) $1,2,3$.

(student stops) That's not a step. That goes from $D$ to $F$.

$S$ (olays)

ot

(plays)

T Try it again.

$S$ (plays)

T 0

$S$ (plays)

T OK, try it again. 1, 2, ready, go...

$S$ (plays)

$T$ (while student plays) $1,2,3,4$

(student stops) Listen. (plays) (while playing) $1,2,3,4,1,2,3,4$.

$S$ (plays)

$T$ (while studerit plays) $1,2,3,4,1,2,3,4,1,2, \ldots$. D! . 1, 2. . (student stops) (sings) bum, bum, bum, (stops) Down by step

$S$ (plays)

$T$ That's right! OK. Next line. It's gonna switch hands. You're gonna play the same notes, but you're gonna start with your right hand, and then the left hand is gonno finish off the same 
melody that your right hand just played, OK?

$S$ (plays)

$T$ (while student plays) $1,2,3,4,1,2,3,4 \ldots$

(student stops) OK, that was pretty good, Kristin. Remember, you've got three D's. It's 1, 2, 3. (sings) $1,2,3$ (stops) Like that.

$S$ (plays)

T (while student plays) $1,2,3,4 \ldots$ (student stops) (plays) $1,2,3,4$

$S$ (plays a few notes)

$T$ No, you've gotta play three.

$S$ (plays)

$T$ (while student plays) $1,2,3,4 \ldots$

(student stops) (sings) bum, bum, bum. (stops) OK, Kristin, I want you to learn and memorize those two lines. OK? This is a neat song. Easy to learn. The first two lines and the last two lines are just alike. OK? So I want you to memorize the first two lines for next week. All right. What page is that?

$S$ Sixteen.

T OK. Or Waltz. .. memorize first page. Now, be practicing all of your Woltz, and think about all the things that we talked about today, all right? I'm not gonna give you any more $P$ iano. Just go back over page 34 and learn page 35. All right? Um, your Performance . . you've got two pages in... those two lines to memor ize, and spend a lot of time working on your Waltz. Work on your technique and for theory... . let's see.... . work page 24. Go ahead I'mi gonna check these here. One page. OK, you need to correct this, Kr r istir. On page 23. numiber 7. Drawing your thirds? You need to go back and correct those. A third goes eithier fromi a line to a line, or a space to a space. And look here. Sometimes you've got line to space, space to line. See? These are seconds. You drew seconds, just like you did over here You need to draw thirds this time. OK? Can you remember to do that for me? Theory, pouge 23 and 24 . OK, your practicing. ... very good, Kristin! Eight! That's excellerit! 40 minutes. Real good. OK, you did well. Hope you have a good week! 


\section{APPENDIXD}

TRANSCRIPT OF SAMPLE LESSON:

OLDER STUDENT; MORE-EXPERIENCED TEACHER 
TEACHER EXPERIENCE: 19 YRS.

STUDENT AGE: 15

STUDENT EXPERIENCE: 6 YRS.

PERCEIVED ABILITY: BETTER

TOTAL LESSON TIME: 35.48 .19

ACADEMIC MUSICAL INFORMATION: $45.96 \%$

MODELING: $30.08 \%$

COACHING: $7.04 \%$

TEACHER TALK: $62.28 \%$

DIRECTION: $2.19 \%$

STUDENT PARTICIFATION: $34.29 \%$

PERFORMANCE/VERBAL RATI0: $93 / 7$

VERBAL REINFORCEMENT: $5.83 \%$

AFPROVAL/DISAPPROVAL RATIO: $40 / 60$

SPECIFIC/NON-SPECIFIC RATIO: $52 / 48$

SEQUENTIAL PATTERNS

COMPLETE/CORRECT: $17.24 \%$

COMPLETE/INCORRECT: $39.08 \%$

INCOMFLETE: $43.68 \%$

T Come on in. You look funny coming in empty-handed.

\& Huh?

T Well, you look funny coming in with no books! I'm not used to seeing you come in with nothing in your hands! Here they are Dr. Swanzy ran them off for me, actually.

$S$ Oh, [?]

T That's what I figured. So that you don't have to worry.

$S$ Yeh, that's for sure.

$T$ (to the dog, which has been barking) Boo!

Do you wanna start with this? You know what I should. . I have not been checking up on your scales. Let me ask you about a couple of them. I'm totally depending on that group class for practice. I hope you've been. . .

$S$ No

T You have not been good about it? OK. Let's go.

$S$ When is our [?]. Next week?

T No, uh uh. It's not until the 4th. May 4th is all the playing. But um, Apr il the 27 th is the written. And, by the way, I have those times, so I can give them to you. Where can i write 
this that you'll remember? You want me to just get you a piece of paper? Is Steven coming with your notebook?

S Um hmm

$T$ Huh? Did you say yes, or no?

$S$ Yes.

$T$ Oh. I just can't hear you. All right. Let me give you the information here, and you can transfer it, in case he forgets it. On April the 27th. . . you're doing, this is Theresa. . . Nothing to do with Steven. I'll do Steven's times separately. Um, this is the written part of the Rally, the written test part. You are in 9th grade, correct? So you're Level 3. You have a choice of either going at 9 AM, or 12:45. You do not need to tell me or anybody else when you're going. You just chaose the time you wanna go, OK? And go. Steven. Let me do. . let me do this. May the 4 th, you do all of your playing, and you do that at $3: 15$. And that's the 3 pieces, performance, 3 pieces, keyboard, and sight-reading. Now do you know what keys you're supposed to be playing your scoles in?

S $B, E, A, D$ ?

$T$ B-flat, E-flat, $A$-flat, $D$-flat, $G$-flat, um. .F, $C$, and $G$ major. .F, $C$, and $G$ minor. Did you practice those? Enough?

$S$ No

$T$ Not enough. All right. Let's see B-flat major.

$S$ (ploys)

$T$ You must do that in four octaves, so start lower.

$S$ (plays)

$T$ CK. Stop and do the left hand alone. Fingering for the left hand in B-flat is just like the fingering for $E$-flat and A-flat. All three of these scales, and ever um . uh let's see, B-flat, E-flat, A-flat. If you remember when you first turn over, your first batch of fingerings, 4 . Then you'll be OK. In the left hand (plays) (while playing) 3,2, 1, 4. (stops) OK. Try it. Left hand alone.

$S$ (plays a few notes)

T No. 3, 2, 1 .

$S$ (plays)

$T$ Hold your hand a little bit higher so that when it's time to play your thumb, you don't have to kick sideways like that. And in fact, you thumb can get underneath your hand (plays) without you going like that. All right? Try it one more time left hand alone. Hold it nice and steady all the way across as if. . suppose I had a. . suppose your hand was a pull toy. Do you know what a pull toy is? A little toy that has wheels and a little baby pulls it with a string? OK. I've got a string here, and I'm just gonna pull vour hand and it's a toy. Don't change it's shape. Freterid your toy is made out of wood, and it's. . it's not gonna change its shape. ok? Try it. 
$S$ (plays a few notes)

$T$ No. Nope.

$S$ (plays)

$T$ (while student plays) All right. On the way back, get that thumb under. That's it! (student stops) OK. Hands together. Four octaves.

$S$ (plays)

T Ahn! One mare octave.

$S$ (plays)

$T$ Theresa. What finger played B-flat in the right hand all the way up?

$S$ Three?

T Tryit.

$S$ (plays)

T All the way up, huh?

$S$ (plays)

$T$ What finger plays B-flat in the left hand all of the time? Try it.

S 3 ?

T 3. They don't match. Now once you start trying to match, you're gonna lose it. OK. Let's try

it again slowly enough where you could think before you put a finger on a flat key.

$S$ (plays)

$T$ Got it! Finish of the routine. First comes scales, then comes inversions of the one and the four and the five chord.

$S$ (plays)

$T$ Stop. Fingering, fingering, fingering:

$S$ (plays a few chords)

$T$ Uh uh. Left hand.

$S$ (plays)

$T$ Whoa, where'd you get those notes? Where did you get an $E$ and $a G$-sharp, and a $B$ natural in. the key of $B$-flat?

$S$ [?]

$T$ Tell me what you're playing! What key are you playing in?

$S$ B-flat.

$T$ B-flat major!

$S$ (plays a few notes)

$T$ You'd better play that scale again and find out what the four th note of the scale is!

$S$ (plays)

$T$ Uh uh. Uh uh. Fingering. It's gone out the window.

$S$ (plays)

$T$ Un uh.

$S$ (plays) 
T OK

$S$ (plays)

$T$ No. Fingering, and an incorrect note.

$S$ (plays)

$T$ Do it once again. Root position

$S$ (Plays)

$\mathrm{T}$ (while student plays) 1st inversion, 2nd inversion....

(student stops) You've gotta slow down and pay attention to what you're doing. You're wasting a lot of time here. Which inversion in the right hand uses the second finger?

$S$ First

T Only the first. Which inversion in the left hand uses the second finger?

$S$ Second

$T$ Only the second. OK. don't try to put them in anywhere else. Let's go.

$S$ (plays)

$T$ Five chord

$S$ (plays)

$T$ Cadence. One, four, one, five..

$S$ (plays)

T What's., you. . What's your fourth note of the scale? Don't lose sight of that. What's the fourth note of the scale?

$s$ (plays a note)

T No it's not!

$S$ (plays a few notes)

$T$ So when you play a four chord, it's obviously gotta have an $E$-flat in it, right? OK, let's go

$s$ (plays)

T OK. What's next?

$S$ (plays a few notes)

$T$ Yes. Arpeggio.

$S$ (plays)

$T$ Un uh.

$S$ (plays)

$T$ That's correct.

$S$ (plays)

T Nope. Left hand does. . do you have your book at home that shows all of these finger ings? It'scalled Intermediate Musicianship, or Elementary Musicianship?

$S$ Um nmm

T Well you have. you better look these up. I don't have time in a half hour lesson to g: through all. .all of these keys, and make sure you're practicing the corr rect fingers. I 
thought you were doing this in group.

$S$ No, she comes in too late. Twenty minutes late.

$T$ Every week?

$S$ Um hmm. Every week.

$T$ And you never do keyboard?

$S$ No. Getting in the class is [?].

$T$ What time is your class supposed to be?

S $4: 45$.

T And what time does it start? It alwlays starts after $50^{\prime}$ clock?

$S$ Um hmm.

$T$ OK. The left hand arpeggio is $3,2,1$. Left hand, $3,2,1$.

$S$ (plays)

T 321, 3, 2, 1 all the way up.

$S$ (plays)

$T$ The right hand is $4,1,2$. . You need to start down one more octave, so you can play it.

$S$ (plays)

T I'm gonna trust you in the very first day that we practice this week, to get started back on these. You used to do them. In fact, at the beginning of the of the year, I used to ask you for them, arid you were doing them quite easily.

$S$ Um hmm

T But. go ahead and pull that book out and start working on these. Any one that you're doubtful of, look it up, and make sure you're doing the correct ones. You have got to get thase back in your fingers. All right, let's go with Bach.

$S$ (plays)

$T$ it's nice and steady! When you begir... when you begin the, not at the right hand entrance of the subject. . The entrance of the subject in the right hand seems pretty straight to me (plays). Eut there's something jazzy about the left hand. I can't. . I can't exactly tell you. It seems like you're going... OK, this is an exagger ation of what I hear you do. This is not.. What you do is not this bad. but this is what is seemed like. (plays). You know, like a boogie-woogie beat? Sol think what must be happening, is you might be. . remember when you first started, I told you to try to accent the notes that were different? Not to keep playing $C$ very loud, but to play $A, G, F, E$. . to bring those out a little? I think maybe you've gone too much in that direction, and so what's happening is this (plays). It's too much that way now. Let's see if you can make it more even. (plays) Let's try that. I think: maybe that's. . and start it right here on the $G$.

$S$ (plays a few notes)

T Wait, don't punch those bottom notes anymore. Don't punch them. Do not purch the botton: note.

$S$ (plays) 
T (while student plays)Make it just a little... No.

(student stops) Make. . make (plays) (while playing) da-da-da-da-da-da-da-da-da-dada-da-da-da-da. (stops) Just don't try to do what I asked you to do before.

$S$ (plays)

T (while student plays) (sings) (student stops) That's right. Now try that

$S$ (plays a few notes)

$T$ (while student plays) (sings). . OK, now. (student stops) Let's start it off, a little bit on the soit side with that $C$.

$S$ (plays)

$T$ (while student plays) Da-da-da-da-and more and more and more and more and more and da-da-da-da-da-da. That's right. OK, now.

(student stops) Let's just go ahead and play the beginning, from the beginning to about there, and then we'll stop. See if we can make it. Two hands together.

$S$ (plays)

$T$ (while student piays) (sings) (student stops) Much better. That's much better, Theresa. That's much better. All right. So, what.. What I can say ther $\epsilon$ is. . . Oh, I need an assignment sheet! It drives me nuts!

$S$ What. . do want me to accent them?

T No, dor't accent them anymore. Don't accent them anymore. You, you've got it. what you've got built in is. . is holding. it's holding the beat. Uh, you were over doing it. Now wher, iten! you to stop doing it, there's still some. . just enough left in there, where you don't have to try to accent anymore. You're keeping the beat very well. And I can hear the outline of the piece. I can hear it going down (plays), I can hear that, without you pok ing out at me arymore (plays). I can still . (sings), I car still hear that happening, so dor't accent that anymiore Don't. . poke.. at lower notes. . in the subject. That tock care of it I mean, just literally ironed it nice and smooth. Um, can we go over. . hop over here to the end. You're not holding your quarter notes. There are. . there is a quar ter note on every beat, there's one. I don't wanna do this in brown, because I don't wanna ruin my. .my, ..00oh!

Excuse me. . red voice, green voice, blue voice things gning on here.

$S$ (plays a few notes)

$T$ Let's. , starting from here. Yeh.

$s$ (plays a few notes)

$T$ But, you see, they're not all loud. It's the red that's gonna be loud, but you still have to hold this. (plays). OK, see how soft. Let's go.

$S$ (plays)

T (while student plays) Soft, loud, loud, loud, loud. no. (student stops) This is soft. 


\section{T\&S (play)}

T (while playing) Loud, loud, loud, loud... (student stops) Right.

$S$ (plays)

$T$ No. Watch that $B$. That $B$ helongs to this little grouping right here; $A, G, A, B$.

$S$ (plays a few notes)

$T$ (while student plays) Soft, loud, loud, loud. (student stops) Go ahead.

T\&S (play)

T (while playing) Soft, loud, loud, loud, loud . . . . . loud loud loud loud. . loud loud. . . . loud loud loud. . . da. . da, dum da. (stop) OK. Play it slow, very slow, and I'm gonna play only the loud parts with you. You're gonna play bath. I'm gonna only play the loud. Ready, go.

$T \& S$ (play a few notes)

T Whoa! No! OK.

T\&S (play a few notes)

$T$ Un uh. That $A$ is not a loud voice.

$S$ (plays a few notes)

$T$ Right. Here's a loud voice (plays). Oops. (plays). That's the only thing that's loud. Go. do it again.

$S$ (plays)

T OK. Can you play both voices together? Slow enough so that you can just play that line for me. Ready?

$S$ (plays a few notes)

I Well, you don't. . you don't. . Don't hit that quite so hard, now. I mean, it's a loud voice (plays), (while playing) but it goes to there (stops) (plays) Ba-da-da-da-dum. . . bada-da-dum. (stops) Ready? Play both.

$T \& S$ (both play)

$S$ (plays alone)

$T$ OK. This. , this dotted-eighth note has to be held.

$S$ (plays)

$T$ [?] (plays)

$S$ (plays)

T (while student plays).... da-one... (student stops) but don't hold them both. (plays) (while playing) This is what you hold.

$S$ on.

$T$ Legato. OK, let me do it slowly. (plays) Wait. I'm not doing it right Yeh, [?]. I'm teaching you, and I'm doing it wrong. (plays). Can you do just that much?

Tixs (both play) 
T All right.

T\&S (both play)

$T$ Again.

T\&S (both play)

T You know what happened here? (pause)...... This still sounds messy. But this sounds wonderful. This isn't. . this isn't quite loud enough. This is. . If you could play this one like you play this one, I guess. . I guess the reason why it doesn't come out as well is because of this going at the same time. So. . if you could just try to br ing that out. Let me see if I can help you a little bit more on this line. It's like the last line. . It's like the last thing that's not working. Uh...

$S$ (plays a note).

$T$ You begin on that $A$. That is the subject.

$S$ (plays).

$T$ Oh. Goon.

$S$ (plays)

T (while student plays) That was nice.

(student stops) That was nice. I. . obviously you know what to do, it's just hard. sometimes it doesn't sound like it's coming out. These last five notes before the entrance of the subject. . . The entrance of the subject is that particular A, right there. You know that, dorit you? And this A right before it has to not be quite so loud. You see this decrescends mark under neath? This is a true decrescendo. . I mear you really have to do this to these foui. five notes, because if you don't, it won't sound like you're starting something I mean, this dues not sound like the entrance of a subject. (plays) it has to (plays). Then you. . it's like, OK, we're coming to the end of something ( $p l a y s$ ), then you start a little bit upor the loud side, compared to those notes. (plays). Hear it? (plays) Can you do that witt the right: hand only?

Tis (Joth play)

$T$ That's it. That's it. All right. Now... Um... We got the jumpiness out of it. We voiced the enc. . prepared that subject. OK, we have to bring that out a little bit. The rest of it's coming along very nicely. Watch... last . two measures. And to do that, do two things, hold quarters. ... without accent. Two ... top twice loud. . and voice slow. OK. You undersiand all that. Just sit there and do it slowly before you incorporate it into your speed. All right We dan't have any timie for this! You don't have a holiday coming up in school, huh? Where! could get you over here for some more time?

$S$ On the weekend.

$T$ Youdo?

5 Excert for the second. . [?]

$T$ Except for the second piece? or the second part of it, you mean? 
S Yeh, like... this little part.

T You wanna try it? Steal some time from Steven.

$S$ (plays)

$S$ (while student plays) .....All right. . Since you've got this by memory, let me.... (student stops) Let me make best use of our time. . . best use of our time. Andantino con moto. Can you translate?

$S$ I think it's. . a little slower. .

$T$ It's faster than Andante, right. It's a, , little. . It's a little faster than walking. How about this?

$S$ With motion?

T That's correct. So . it. .. it moves. It's not. . it's gonna be. I might be able to find you a spot on there.

$S$ (ploys)

$T$ At least that fast. Maybe faster later on, but right now, at least that fast. (plays). $1,2,3$, $4,1,2,3,4,1,2,3,4$ (metroriome on). No... (metronome on). . 1, 2, 3, 4

$S$ (plays a few notes)

T Start it . start it around here. Yes Like that. 63. .try it. Go ahead

$S$ (plays)

$T$ (while student plays) $1,2,3,4,1,2,3,4$. Now....

(student staps) (sings). So, crescendos, yes. But you know the secret of a really gaiod crescendo is the starting note. If it's just perfect, then the rest of it's easy, right? OK, let's try it agoin.

$s$ (plays)

T (while student plays) (sings)....... OK....(sings)... That's when you have to get tack to this. You let the thing tick away...

(student stops) You do a ritardando, yes. But you lister to it here. You forget it here, and you listen to it here. All right, now that's essentially what I wanted to get across. Uni... (pause)... I always think ! know what it means, and then I tell a student the wrong thing

$S$ (plays a few notes)

T I think it means to hur ry it. I'm almost positive it means to hurry it. I think I have... doggone it! Steven, do you have your notebook with you?

$S$ No, 1 lost it.

T Do you have Theresa's notebook with you? Will one of you please bring a notebook her $\varepsilon$ ? Go get a new one, or somebody bring a notebook, please! I was correct. It means to push it, push it, push it, and then ritard. (sings) .... push. Fush a little in speed, speed it a little. And aiway's crescerido. It star ted crescendoing back here. Woy back here. And it always ought. . sempre crescendo means to keep. . just keep going with the crescendo till it gets realiy big and then, go softer. Go softer. Um. . Hmm? 
$S$ [?]

T A tempo. A tempo. Poco moto?

$S$ A little motion.

$T$ A little motion. A little. . a little faster. A little more fast than it was. So, even though you've memorized it, use the music this week for your expressive directions. Most of these, if not all of them, are straight from Debussy. They're not some editor's idea. Most of them are from him. . his manuscript. Tempo rubato. Stretchy tempo. Give and take. Speed it up, slow it down, speed it up, slow it down. Be expressive about it when it feels like it should stretch, stretch. When it feels like it should hurry, hurry. But I don't think there's much left to your. . deciding. I think most of the time he tells you. Um, maybe not. Maybe he's telling you with that word. . stretch. Stretch. Sometimes. And , . but always come back.

$S$ OK.

T Poco meno mosso.

$S$ Little less

T Little less motion. So it's a little slower, than we've been playing. All right? See what you can do with those. Um, I'll see what I can do about getting that extra work. Don't disaproint. me with these scales, Theresa.

$S O K$

T You have. . an already graying lady getting grayer, worrying about it. Don't look. at my hair! (laughs) Tempos....crescendos, etcetera. And your two other pieces. still ... You have to still practice them. We'll make a decision in probably the next week of class. I forgot the other piece! He!p! Haydn, right? What did you just say?

$S$ The Spinning Wheel

T No! Not the Spinning wheel!

$S$ No, it's the [?]

T Um hmm No! !t's Haysn, Each, and....

5 Nocturne or Debussy

T ...either Debussy or Nocturne. This is. , this is gonna be a substitue for Debussy. Or? Ugh! Nervous, nervous! 


\section{VITAE}

Donald Ray Speer was born June 15, 1961 in Grand Rapids, Michigan. He attended Peabody Magnet High School in Alexandria, Louisiana, graduating in May 1979. He received the Bachelor of Music in Piano Performance from Louisiana College, Pineville, Louisiana, in August 1983. He received the Master of Music in Piano Performance from Southern Illinois University at Edwardsville, in June 1985.

Currently employed as an independent piano teacher in Baton Rouge, Louisiana, he also holds a part-time position as Minister of Music at Riverdale Baptist Church in Baton Rouge.

Married to the former Alesia Hardy, Donald is the father of three children; Colleen Elizabeth, Jordan Daniel, and David Ryan. 
DOCTORAL EXAMINATION AND DISSERTATION REPORT

Candidate: Donald Ray Speer

Major Field: Music Education

Title of Dissertation: An Analysis of Sequential Patterns of Instruction in Piano Lessons

Approved:

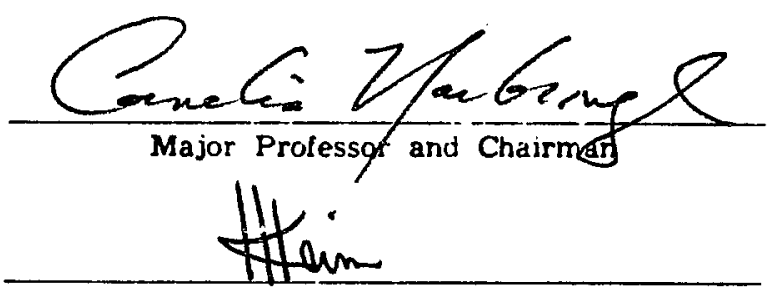

Dean of the Graduate School

EXAMINING COMMITTEE:
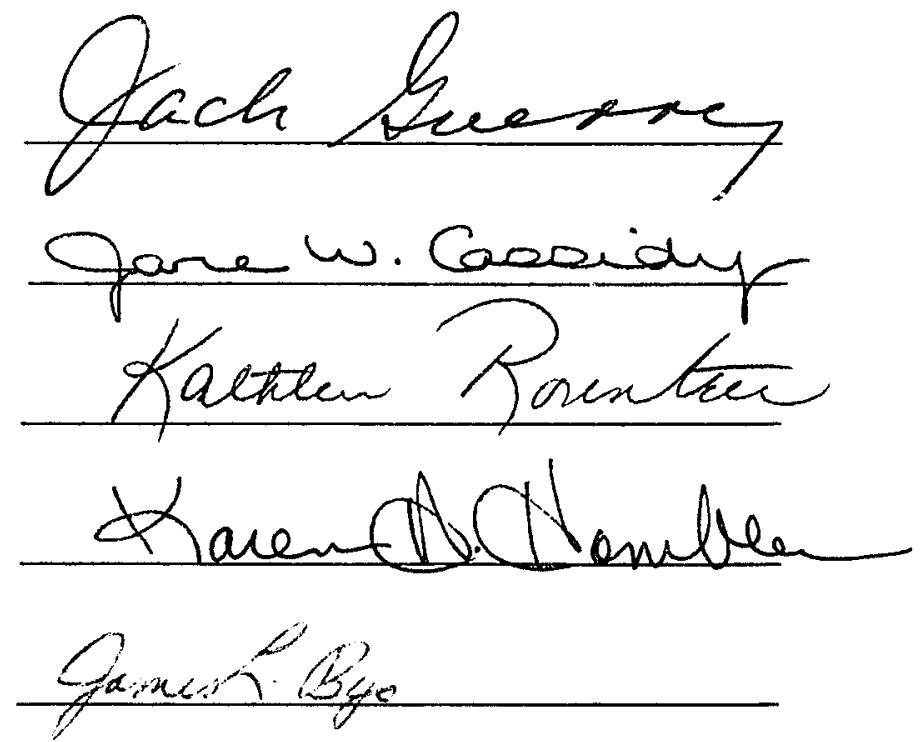

Date of Examination:

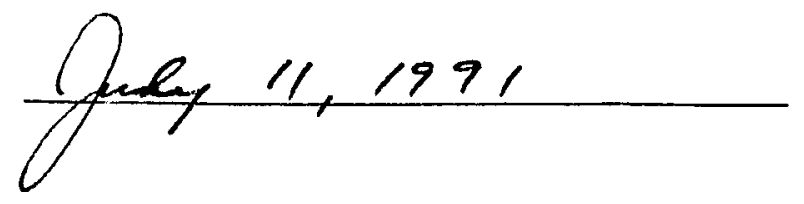

